A UNITED STATES

DEPARTMENT OF

COMMERBE

PUBLICATION

\section{Thermal}

NBS TECHNICAL NOTE 385

\title{
Conductance at the Interface of \\ a Solid and Helium II (Kapitza Conductance)
}




\section{NATIONAL BUREAU OF STANDARDS}

The National Bureau of Standards' was established by an act of Congress March 3, 1901. Today, in addition to serving as the Nation's central measurement laboratory, the Bureau is a principal focal point in the Federal Government for assuring maximum application of the physical and engineering sciences to the advancement of technology in industry and commerce. To this end the Bureau conducts research and provides central national services in four broad program areas. These are: (1) basic mcasurements and standards, (2) materials mcasurements and standards, (3) technological measurements and standards, and (4) transfer of technology.

The Bureau comprises the Institute for Basic Standards, the Institute for Materials Research, the Institute for Applied Technology, the Center for Radiation Rcsearch. the Center for Computer Scicnces and Technology, and the Office for Information Programs.

THE INSTITUTE FOR BASIC STANDARDS provides the central basis within the United States of a complete and consistent system of physical measurement; coordinates that system with measurement systems of other nations; and furnishes essential services lcading to accurate and uniform physical measurements throughout the Nation's scientific community, industry, and commerce. The Institute consists of an Office of Measurement Services and the following technical divisions:

Applied Mathematics-Electricity-Metrology-Mechanics-Heat-Atomic and Molecular Physics-Radio Physics - - Radio Engineering "-Time and Frequency - - Astrophysics"-Cryogenics."

THE INSTITUTE FOR MATERIALS RESEARCH conducts materials research leading to inproved methods of measurement standards, and data on the properties of well-characterized materials needed by industry, commerce, educational institutions, and Government; develops, produces, and distributes standard reference $m$ atcrials; relates the physical and chemical properties of materials to their behavior and their interaction with their environments; and provides advisory and research services to other Govcrnment agencies. The Institute consists of an Office of Standard Reference Materials and the following divisions:

Analytical Chemistry-Polymers-Metallurgy_Inorganic Materials_Physical Chemistry.

THE INSTITUTE FOR APPLIED TECHNOLOGY provides tcchnical services to promote the use of available technology and to facilitate technological innovation in industry and Government; cooperates with public and private organizations in the dcvelopment of technological standards, and test methodologies; and provides advisory and research services for Fedcral, state, and local government agencies. The Institute consists of the following technical divisions and offices:

Engincering Standards-Weights and Measures - Invention and Innovation - Vehicle Systems Research-Product Evaluation-Building Research-Instrument Shops-Measurement Engineering-Electronic Technology_Technical Analysis.

THE CENTER FOR RADIATION RESEARCH engages in research, measurement, and application of radiation to the solution of Bureau mission problcms and the problems of other agencies and institutions. The Center consists of the following divisions:

Reactor Radiation-Linac Radiation-Nuclear Radiation-Applied Radiation.

THE CENTER FOR COMPUTER SCIENCES AND TECHNOLOGY conducts research and provides technical services designed to aid Government agencics in the selection, acquisition. and effective usc of automatic data processing equipment; and scrves as the principal focus for the development of Fedcral standards for automatic data processing equipment, techniques, and computer languages. The Center consists of the following offices and divisions:

Information Processing Standards-Computer Information - Computer Scrvices - Systems Development-Information Processing Technology.

THE OFFICE FOR INFORMATION PROGRAMS promotes optimum dissemination and accessibility of scientific information generated within NBS and other agencies of the Federal government; promotes the devclopment of the National Standard Reference Data System and a system of information analysis centers dealing with the broader aspects of the National Measurement System, and provides appropriate services to ensure that the NBS staff has optimum accessibility to the scientific information of thc world. The Office consists of the following organizational units:

Office of Standard Reference Data-Clearinghouse for Fcderal Scientific and Technical Information "-Office of Technical Information and Publications-Library-Office of Public Information-Office of International Relations.

\footnotetext{
Headquarters and Laboratories at Gaithersburg. Maryland, unless otherwise noted; mailing address Washington, D.C. 20234. Located at Boulder. Colorado 80302.
}

${ }^{3}$ Located at 5285 Port Royal Road, Springfield, Virginia 22151. 
UNITED STATES DEPARTMENT OF COMMERCE

Maurice H. Stans, Secretary

NATIONAL BUREAU OF STANDARDS - Lewis M. Branscomb, Director

\title{
NBS TECHNICAL NOTE 385 ISSUED DECEMBER 1969
}

Nat. Bur. Stand. (U.S.), Tech. Note 385, 90 pages (Dec. 1969) CODEN: NBTNA

\section{Thermal Conductance of the Inferface of a Solid and Helium II (Kapitza Conductance)*}

\author{
N. S. Snyder \\ Cryogenics Division \\ Institute for Basic Standards \\ National Bureau of Standards \\ Boulder, Colorado 80302
}

* This work was carried out at NBS under the sponsorship of the U.S.

Atomic Energy Commission, Contract Agreement AT (49-2)-1165.

NBS Technical Notes are designed to supplement the Bureau's regular publications program. They provide a means for making available scientific data that are of transient or limited interest. Technical Notes may be listed or referred to in the open literature. 

LIST OF FIGURES ....................... vi

LISTOF TABLES........................... vii

1. INTRODUCTION .................... 1

2. PHONON RADIATION LIMIT ............ 4

3. EXPERIMENTAL DATA FOR $\triangle \mathrm{T}<<\mathrm{T} \ldots . . . . .8$

3. 1. Comparison with the Phonon Radiation Limit ... 8

3.2. Reproducibility of Experiments ........ 10

3.3. Empirical Analysis of Data.......... 13

a. Surface condition ............... 13

b. Correlation with molecular weight and elastic properties ................. 19

c. Metals-effect of electrons......... 24

4. THEORIES OF KAPITZA CONDUCTANCE ....... 30

4. 1. Acoustic Mismatch ................. 31

4.2. Electron Mechanisms and Surface Disturbances.. 38

4.3. Thermal Accommodation .......... 40

5. INTERFACE CONDUCTANCE WHEN $\triangle \mathrm{T} \sim \mathrm{T} \ldots \ldots$ 4́

5. 1. Kapitza Region ............ 46

5.2. Pre-Film Boiling Region ......... 47 



\section{LIST OF FIGURES}

Page

Figure 1. Kapitza conductance at 1.5 K - largest values for each solid are plotted..............

Figure 2. Kapitza conductance at 1.9 K for cleaned surfaces .

Figure 3. Kapitza conductance at $1.9 \mathrm{~K}$ for polished surfaces..

Figure 4. Kapitza conductance at 1.9 for unpolished, oxided surfaces

Figure 5. Kapitza conductance at $1.9 \mathrm{~K}$ for chemically clean, unstrained surfaces plotted against $1 / \rho c_{t}^{3} \ldots . . . ., 34$

Figure 6. Kapitza conductance of Ag for large $\Delta \mathrm{T} . . . . .$.

Figure 7. Maximum values of the peak heat flux density for horizontal cylinders............ 50

Figure 8. Reduced peak heat flux as a function of temperature. .

Figure 9. Pressure dependence of the maximum peak heat flux.

Figure 10. Peak temperature difference for several surfaces... 


\section{LIST OF TABLES}

Page

Table I. Compilation of Kapitza Conductance Data . . 62

Table II. Comparison with Phonon Radiation Limit -

Metals (1.9 K) . . . . . . . . 76

Table III. Comparison with Phonon Radiation Limit --

Non-Metals (1.9 K) . . . . . . . 77

Table IV. Measurements of Kapitza Conductance for Copper

$[1.9 \mathrm{~K}]$. . . . . . .

Table V. Measurements of Kapitza Conductance for Lead

in Normal State $(1.9 \mathrm{~K}) \quad . \quad . \quad . \quad . \quad . \quad 80$ 
ABSTRACT

A review is presented of the experimental and theoretical work on Kapitza conductance, including a compilation of the available data on conductance to helium II. A short derivation of the phonon radiation limit indicates the reason for the approximate $\mathrm{T}^{3}$ temperature dependence and the small size of the Kapitza conductance for most solids. Considerable qualitative and quantitative correspondence of the data with this limit is found. From the limited evidence available, the role of surface conditions, and of bulk parameters such as the Debye temperature in determining the conductance are considered empirically. Theoretical knowledge of the Kapitza conductance is seen to give an inadequate explanation of the data. In addition, the phenomena which occur when the heat flux is high enough that properties of the bulk liquid are also involved in the measured conductance are described briefly.

Key Words: Heat transfer; helium II; Kapitza conductance. 
THERMAL CONDUCTANCE AT THE INTERFACE OF A SOLID AND HELIUM II (KAPITZA CONDUCTANCE)

by

N. S. Snyder

\section{INTRODUCTION}

When a heat flow per unit area, $Q$, occurs across a solid-liquid interface, it is found to be limited by a finite conductance, $h_{k}$, which is well-defined and independent of heat transfer processes in the liquid as $\Delta \mathrm{T}$, the temperature difference between the solid and liquid, approaches 0.

$$
h_{k}=\lim _{\Delta T \rightarrow 0} \frac{Q}{\Delta T}
$$

In the limit of $\Delta \mathrm{T} \ll \mathrm{T}_{\ell}$, where $\mathrm{T}_{\ell}$ is the liquid temperature, $\mathrm{h}_{\mathrm{k}}$ is expected to be the same for heat flow in either direction. When $\Delta \mathrm{T}$ is large, however, convection and other processes in the liquid become important and reversibility is not expected. A discussion of the se latter effects is postponed to Section 5, since the emphasis in the present paper is on interface properties. High $\Delta \mathrm{T}$ experiments are also considered more fully in a recent review paper of Frederking (1968). 
To measure $h_{k}$ by the conventional steady state method, at least two temperature sensors are required in the solid to give an extrapolated temperature value at the interface. By choosing helium II for the liquid, the temperature at the liquid side of the interface is well-defined, and in fact the first measurements of solid-liquid interface conductance were made by Kapitza (1941) using helium II. Kapitza and later investigators found that $h_{k}$ varies approximately as $\mathrm{T}^{3}$, where $\mathrm{T}$ is the absolute temperature, which indicates why interface thermal resistances were not observed first at higher temperatures. Magnitudes of the interface conductance at $1.9 \mathrm{~K}$ have been found to range between 1. to $50 \mathrm{~kW} / \mathrm{m}^{2} \mathrm{~K}$ for the 19 solids investigated thus far. Because of these magnitudes and the temperature dependence, the interface conductance is found to be the limiting factor in many cases of heat generation for which helium II cooling is necessary. Interface conductance assumes even more importance at temperatures in the millikelvin range at which $\mathrm{He}^{3}$ dilution refrigerators operate.

A qualitative understanding of the temperature dependence and variation of $h_{k}$ with solid properties can be obtained from thermodynamic considerations and a simple model of a solid at low temperatures. This is discussed in Section 2. The experimental work on interface conductance to date has been fairly limited, in terms of both the range of solids investigated and the characterization of surface conditions at 
the interface. Considerable disagreement exists between results for samples of the same solid. Table I presents the available data for all solids. The experimental results and some empirical correlations that may be derived from the measurements are treated in Section 3. Theoretical work has been based mostly upon the acoustic mismatch theory of Khalatnikov (1952), (1965), but experimental results do not agree qualitatively or quantitatively with the theories. For this reason, the treatment of theories in Section 4 is brief. An extensive discussion is available in a review by Pollack (1969).

In addition to the presentation of a complete tabulation of the experimental results, the present discussion differs from the previous reviews of Frederking (1968) and Pollack (1969) in several ways. The treatment of the interface conduction problem (low $\Delta T$ ) is more detailed than that presented by Frederking, who emphasizes the high heat current region. The present discussion differs from Pollack's review in that it is oriented primarily toward presentation of design information.

There are also several differences between this discussion and that of Pollack regarding the interpretation of the data (See Sections 3.3 and 5). Perhaps the most important aspect of the present study is the correlation noted between the phonon radiation limit and some of the data (Sections 2 and 3.1). The phonon radiation limit is not mentioned by Pollack, and its applicability to non-metals, and clean metal surfaces is not discussed by Frederking. 


\section{PHONON RADIATION LIMIT}

The small size of the Kapitza conductance at low temperatures follows simply from an application of thermodynamics to well-established models of a solid. Heat can be transported through the bulk solid both by conduction electrons and by vibrations of the atoms, but since heat transfer at an interface probably involves chiefly the lattice vibrations, the case of an insulator will be considered first. When the vibrations of the atoms are treated by the methods of quantum mechanics, the solution in terms of traveling waves is restricted to certain normal modes with discrete energies, each of which obeys the classical equations of motion of a harmonic oscillator. (See, e.g., Klemens, 1958.) These quantized modes of vibration are referred to as phonons, by analogy with photons, which are the quantized electromagnetic waves. The change in the atomic vibrations with temperature is described in terms of an increase with temperature in the number of phonons excited for each discrete energy level. The heat conduction process in an insulator may be understood by considering the phonons to be particles of a "gas" with a mean free 
path between collisions of the phonons with each other and with defects and boundaries of the solid. A higher density of phonons at the hot end of a solid then results in a net flow to the cold end. Because the lattice contribution to the specific heat of most solids at low temperatures has a $\mathrm{T}^{3}$ dependence, the energy density of phonons in this temperature region is given by

$$
\mathrm{U}=\mathrm{a} \mathrm{T}^{4}
$$

where $a$ is a factor which depends upon properties of the solid. This equation has the same form as the blackbody radiation law for the electromagnetic energy radiated by photons, which also have some of the kinetic properties of a gas.

Now, if the interface resistance is considered to be localized to within a distance of one phonon mean free path on both sides of the boundary surface, the reason for a thermal barrier can be understood by considering the analogous problem of heat conduction in a low pressure gas. In this case, for distances less than the mean free path, the heat flow is limited by the number of molecules, or the pressure, and for a solid, the heat flow will be limited by the available number of phonons, which decreases rapidly as the temperature decreases. According to the usual kinetic result, the heat flux across a plane is

$$
\mathrm{q}_{\rightarrow}=\frac{1}{4} \mathrm{U} \overline{\mathrm{c}}=\frac{1}{4} \mathrm{a} \overline{\mathrm{c}} \mathrm{T}^{4}
$$


where $\bar{c}$ is the average velocity of the phonons and the arrow indicates flow in one direction. Then the net heat flux across a layer with one side at temperature $\mathrm{T}$ and the other at $\mathrm{T}+\Delta \mathrm{T}$, where $\Delta \mathrm{T}<\mathrm{T}$, is

$$
\dot{\mathrm{Q}}=\mathrm{a} \overline{\mathrm{c}} \mathrm{T}^{3} \Delta \mathrm{T}=\mathrm{h}_{\mathrm{k}} \Delta \mathrm{T} \text {. }
$$

The constant a for the solid will be the limiting factor in (4) because phonons are more easily excited in helium II. In deriving this expression the assumption of perfect transmission at the interface was implicitly made; hence (4) gives the upper phonon radiation limit for the conductance that may occur across a realinterface. If the mechanisms that may cause less than perfect transmission are not strongly temperature dependent, the $\mathrm{T}^{3}$ dependence should be a good approximation for the real interface. The actual mechanism of energy transport across the interface is still unspecified in (4), which only states the thermodynamic basis for the thermal barrier. Although for non-superconducting metals the electrons also participate in heat transport, unless surface waves are important (Little, 1960), or unless the electron wavefunctions "leak" across the boundary (Johnson and Little, 1963), the electrons must give up their thermal energy to phonons before it is transmitted across the interface, so the upper limit expressed by (4) remains valid. 
The factor a, which is different for each solid, can be obtained in theory from an integration involving the dispersion relation for phonon energy versus wave-vector. This dispersion relation can be obtained either from neutron and $\mathrm{x}$-ray scattering data or from a theoretical calculation based upon the forces between neighboring atoms. At low temperatures, however, the integral over the detailed spectrum can be characterized to a good approximation by a single parameter, the Debye temperature, $\Theta_{\mathrm{D}}$. For example, for temperatures below about $\Theta_{\mathrm{D}} / 50$, the specific heat is proportional to $\mathrm{T}^{3} / \theta_{\mathrm{D}}{ }^{3}$. The Debye approximation and the evaluation of $\Theta_{D}$ from specific heat or elastic constant measurements is discussed in many texts (Kittel, 1966). Roughly speaking, a high $\Theta_{D}$ corresponds to a lattice with strong interatomic forces and light atoms. In this approximation the phonon radiation limit is

$$
h_{k}=\frac{2 \pi^{4} k^{2}}{5 \theta_{D}^{2} \hbar}(3 N / 4 \pi)^{2 / 3} T^{3},
$$

where $\mathrm{N}$ is the number of atoms per unit volume and the other symbols have their usual meaning. Evaluating (5) for copper, which has a Debye temperature of about $343 \mathrm{~K}$, gives a conductance of $4.45 \times 10^{3} \mathrm{~T}^{3} \mathrm{~W} / \mathrm{m}^{2} \mathrm{~K}^{4}$. Lead has a considerably lower $\Theta_{D}$ of about $100 \mathrm{~K}$, which gives a conductance of $2.83 \times 10^{4} \mathrm{~T}^{3} \mathrm{~W} / \mathrm{m}^{2} \mathrm{~K}^{4}$. Since few solids of practical inter est have such a low $\Theta_{D^{\prime}}$ it is illuminating to note that the approximate 
upper limit of the interface conductance of lead at $1.9 \mathrm{~K}$, which is $1.9 \times 10^{5} \mathrm{~W} / \mathrm{m}^{2} \mathrm{~K}$, is comparable with the conductance through $175 \mathrm{~km}$ of a tube filled with superfluid helium at $1.9 \mathrm{~K}$. (This comparison is valid for laminar flow conditions: for example, heat flux less than about $2 \times 10^{2} \mathrm{~W} / \mathrm{m}^{2}$ through a $10 \mathrm{~mm}$ diameter tube. Arp; 1970). This shows why Kapitza conductance is the limiting factor in many situations of heat transfer to superfluid helium. For heat transfer with higher fluxes which cause non-laminar flow, the conductance through the liquid becomes more comparable to the Kapitza conductance.

\section{EXPERIMENTAL DATA FOR $\triangle \mathrm{T}<<\mathrm{T}$}

3.1. Comparison with Phonon Radiation Limit

Table I is a compilation of all experimental measurements of the Kapitza conductance of various solids. (Some indirect measurements of low accuracy have been excluded.) To date (Sept. 196́9), 19 solids have been investigated; prominent examples of solids of technical and theoretical interest for which no data are available include $\mathrm{Al}, \mathrm{Be}$, Ge, Fe, brass, stainless steel and high field magnet alloys, glass and plastics. In Table I, the range of temperatures over which measurements were made is indicated in each case, but the conductance is quoted only at $1.9 \mathrm{~K}$ since this is usually an optimum temperature for heat transfer processes with helium II. (See Arp, 1970). If the authors reported a temperature dependence, this is also presented. Table I 
shows that the $\mathrm{T}^{3}$ law is approximately obeyed for a variety of solids, although the actual exponent of $T$ ranges from 2.6 to 4.2. There is some indication that below about $0.1 \mathrm{~K}$, conductances for solid-solid interfaces follow a $\mathrm{T}^{3}$ dependence more exactly (Syomi, Anderson, and Holmström, 1968). The conductance between copper and both liquid $\mathrm{He}^{3}$ and $\mathrm{He}^{4}$ also has been found to vary more nearly as $\mathrm{T}^{3}$ at very low temperatures (Anderson, Connolly and Wheatley, 1964). This behavior is expected because the derivation of (5) is valid as $\mathrm{T}$ approaches $0 \mathrm{~K}$. Mercury has a very low Debye temperature, so its specific heat does not follow a $\mathrm{T}^{3}$ law in the temperature range of the measurements. However, the ratio for mercury of specific heat to conductance is approximately constant with temperature (Neeper, Pearce and Wasilik, $1967)$.

In Tables II and III, the highest reported values of the Kapitza conductance at $1.9 \mathrm{~K}$ for metals and non-metals are compared with the phonon radiation limit of (5). For metals (Table II), the most interesting comparisons are those for copper and lead, because these two metals have been most extensively investigated, and data is available for chemically clean, unstrained surfaces which should approximate properties of the bulk solid. The steady state result for copper is about a factor of 4 below the limit and the highest conductance reported for lead is about a factor of 6 lower than the limit. The ac conductance 
observed for a copper foil in a second sound resonator by Brow and Osborne (1958) is about a factor of 1.2 below the limit. Because of an error of a factor of 10 in evaluating the phonon radiation limit for copper, Frederking (1968) apparently did not realize the extent of agreement of this limit with experiment. It should be emphasized that precise agreement with the phonon radiation limit is not expected, because perfect transmission at the interface may not occur, and the one-parameter Debye temperature description of the solid is an approximation. Other metals, with the exception of tin, fall below the phonon radiation limit by larger factors. However, (5) does give a rough idea of the relative magnitudes of the conductance for the different metals.

The non-metallic samples (Table III) are all single crystals. Data for carbon films (Hesser, Chapman, Chang, and Frederking, 196́9) are not included because of the difficulty of defining a Debye temperature. Although only five crystals have been investigated, it is striking that the conductances are much closer to the phonon radiation limit than is the case for metals. The largest disagreement is a factor of 3 for $\mathrm{KCl}$. The ranking of crystals by the magnitude of expected conductance from (5) is confirmed by experiment, which again indicates the usefulnes s of this expression for qualitative guidance.

\subsection{Reproducibility of Experiments}

The chief problem a user of Table I will encounter is the wide variation of the measured conductance between samples of the same solid. For example, the steady state conductances reported for copper 
at $1.9 \mathrm{~K}$ vary from 1.2 to $7.5 \mathrm{~kW} / \mathrm{m}^{2} \mathrm{~K}$. The conductance of even a single sample has been found to change after a period of time (Neeper and Dillinger, 1964). The differences in conductance do not seem to be related to the purity of the bulk solid. It is also unlikely that they can be traced to experimental errors. In almost all cases, precautions have been taken to eliminate parallel paths of heat flow, so that this problem cannot affect the results by more than $1-2 \%$. If the experiments are performed with liquid helium II, there will not be any significant uncertainty about the liquid temperature at the interface. However, for the solid, the interface temperature is usually extrapolated from the gradient measured between two sensors located a finite distance from the boundary. In the case of a dielectric with a long phonon mean free path, one can see that all phonons impinging upon the boundary surface may not come from regions of identical temperature. Also the thermal gradient along a crystal surface may not be uniform near the ends of the crystal. An investigation of these effects in sapphire by Neeper and Dillinger (1964) indicated that they were small. For a metal sample, since part of the heat is carried by electrons, similar trouble could arise if there were simultaneously a mean free path between electron collisions comparable to sample dimensions and a large thermal resis tivity. But disagreements exist even for conductance measurements on metal samples of high purity with negligible thermal gradient effects. 
If such a metal is in the superconducting state, at a given temperature, the conductivity is considerably reduced, and in one case it was necessary to make a theoretical calculation of the extrapolated thermal gradient (Challis, 196́2). Also, if the interface region of a superconductor is strained from the differential thermal contraction of the mounting, the effect on the phonon conductivity may be sufficient to cause a significant error (Challis and Sherlock, 1969). This problem does not affect most of the results in Table I. It will be discussed further in Section 3. 3. c. Because the experimental errors of the conductance measurements are small in comparison with the discrepancies observed between measurements of the same solid, it seems most probable that these variations are due to differences in the condition of the sample surface. For many measurements, the state of the surface with regard to possible cold-working, chemical purity, surface asperity, and similar parameters has not been well-defined. Sizeable changes in the interface conductance of an individual sample have been brought about by varying the surface treatment (Challis, 1962). In some cases the state of the surface layer may affect the extrapolation of the temperature gradient to the interface. For example, an excess thermal resistance could result from poor contact of an oxide layer covering the surface with the bulk metal below it. Dislocation damage from cold-working can extend for a distance of the order of $\mathrm{mm}$ into a metal unless very careful techniques are used. (See 
eg., Young and Wilson, 1961). Since the resistivity due to a high dislocation density can be significant at low temperatures for a pure metal, extrapolation of the bulk temperature gradient to the surface may result in a spurious extra thermal resistance which is indistinguishable experimentally from a true interface resistance. Not enough material preparation details have been given, in most cases, to evaluate this possibility.

A side from such spurious effects, the effect of surface parameters upon the actual heat transfer processes at the interface is highly dependent upon the mechanism postulated for this process. The theories of these mechanisms will be discussed in Section 4. But because none of the theories has been substantiated by the experimental evidence, it is felt that the following empirical analysis of the data with regard to surface and other parameters may be more useful in furnishing estimates of conductance for design purposes. 3. 3. Empirical Analysis of Data

\section{a. Surface Condition}

In Table IV, the results of boundary conductance measurements for copper are ranked by the magnitude of the conductance at $1.9 \mathrm{~K}$. With the exception of measurements 4 and 6 , the seven highest conductances observed refer to surfaces which had had at least some of the cold-worked layer formed during machining and polishing removed chemically. Fur- 
thermore, the highest two conductances are for surfaces which had been partially machined while under liquid helium and then allowed to recrystallize at room temperature for about a week before measurement. Recrystallization should have been considerably facilitated by such a procedure since the impurities that would have become imbedded in the surface during room temperature machining were not present. By contrast, all the surfaces of measurements 8 through 13 (below the dashed line) were subjected to cold-working through machining and polishing. For the lowest three conductances reported, it is probable that considerable oxidation of the surfaces had occurred over long periods of time since no precautions or cleaning procedures were noted by the authors. Oxide layers for the other surfaces with higher conductances, were probably lighter. In some cases, the sample was immersed in helium only a few minutes after etching or polishing, and in other cases, the period of exposure to the atmosphere was limited to one week. The conclusion is that a clean, unstrained copper surface should have a boundary conductance of approximately 8 to $5 \mathrm{~W} / \mathrm{m}^{2} \mathrm{~K}$ at $1.9 \mathrm{~K}$, whereas for a cold-worked, "dirty" Surface, allowance for values as low as 1 to $2 \mathrm{~W} / \mathrm{m}^{2} \mathrm{~K}$ should be made for design purposes. Unless stringent measures are taken to protect a clean, etched surface from oxidation, its surface conductance might decrease somewhat with time if it was exposed to the atmosphere between uses at cryogenic temperatures. The relatively large conductance ob- 
served recently by Goodling and Irey (1969) for a machined surface is a puzzling exception to the above regularities. Although the geometry employed by these authors is different from the other workers, calculations showed that end effects and temperature imhomogeneities were negligible.

The only other solid for which measurements with a variety of surface conditions are available is lead; a similar ranking for the metal in the normal state is given in Table V. Samples which were freshly machined or had had surface layers removed by electropolishing, ion bombardment, or etching all fall above the horizontal dashed line. Samples machined under liquid helium with recrystallization permitted at higher temperatures also fall in this upper region, with the exception of some measurements by Cheeke (1969), which are on the border between the two regions. Samples which did not have special treatment fall below this line and can have conductances that are an order of magnitude less than the highest values. From measurements on the same sample, the deleterious effect of an increasing oxide layer is evident (see Challis; 1962). Wey-Yen (1962) carried out an interesting series of experiments on a superconducting lead sample which was machined under liquid helium, then held at room temperature for one week, remachined under liquid helium and finally kept at room temperature for four months (see Table I). Machining decreased 
the conductance while room temperature recrystallization increased it. These results have been confirmed by recent work of Cheeke (1969). The similarity of behavior noted here for the conductance of lead and copper with variation of surface conditions contrasts with comments of Pollack (1969), that the highest conductances are observed for the cleanest surfaces of lead, but that the reverse is true for copper. This involves the problem of defining a "clean" surface. In comparing data of Challis, Dransfeld, and Wilks (1961) for a polished and an etched copper surface, Pollack described the mechanically polished surface with the lower conductivity, as the cleaner one. However, such a surface will be work-hardened, and may have chemical changes at the surface from the polishing agent. Such a surface is probably a poorer approximation to a simple termination of the bulk than an etched surface is. Other data on copper by Challis (1962) showed a small decrease in the conductance of a mechanically deformed sample after it was annealed. But because the surface was polished for the measurements both before and after the annealing, Challis stated that the rather small conductance difference might be ascribed to variations in the polishing procedure. Hence this example does not necessarily indicate that cold working increases the conductance of copper. With regard to the 
presence of an oxide layer, the experiments of Johnson and Little (1963) seem to show, at first glance, that an oxide layer improves the conductance (See Tables I and IV). But since the state of recrystallization of the surface layer is also a variable here, no definite conclusion can be drawn from these experiments alone.

When one examines the Johnson and Little data in conjunction with the data of other experimenters, though, the trends stated in the first paragraph of this section become apparent; that is, the highest conductances are found for copper surfaces which are a closer approximation to a simple termination of the bulk because of chemical removal of cold-worked, chemically foreign layers. It would clearly be more useful, however, if results from the same experimental apparatus, preferably with the same sample, could be compared with respect to the variation of surface conditions. If experiments were carried out which avoided the problems mentioned above of varying two or more surface conditions simultaneously, the problem of whether lead and copper behave similarly could probably be resolved.

Unfortunately, lead and copper are the only solids for which enough measurements have been made at present to permit some rough conclusions as to the size of conductance to be expected with a given surface treatment. An examination of Table I indicates that from the limited data available, ranking of silicon and platinum would follow the 
same general principles observed above, though the effect of etching on the non-metallic silicon, for example, is very small (Johnson and Little, 1963). However for nickel, indium and tin, Table I shows some cases where recrystallization or removal of a surface layer by electropolishing had little effect or actually resulted in some decrease in conductance. Since electropolishing may cause chemical changes at the surface, the situation here is unclear. 
b. Correlation with Molecular Weight and Elastic Properties Figure 1, due to Challis (1968), shows values of the conductances at $1.5 \mathrm{~K}$ for various solids plotted against the reciprocal of the Debye temperature $\Theta_{D}$ on a logarithmic scale. The highest values reported were used. Although the surface conditions of the solids may vary considerably, there is evidence for some degree of correlation.

Figures 2 through 4 give the same type of plot for the three cases of chemically clean and unstrained surfaces, polished metal surfaces, and untreated, oxided surfaces. The bars indicate the range of results for surface conditions that are approximately the same. The extremely low conductance for electropolished $\mathrm{Ni}$ is not shown in figure 2 (Wey-Yen, 1962). With the possible exception of figure 4, a correlation is again apparent, but the dependence of $h_{k}$ on $\left(1 / \theta_{D}\right)^{n}$ goes as $n \sim 0.8$ in figure 2 and $n \sim 0.6$ in figure 3. The lesser amount of correlation with the Debye temperature for the untreated surfaces of figure 4 demonstrates the need for careful surface preparation to insure a predictable value of Kapitza conductance. However, even for surfaces of the types represented in figures 2 and 3, the predictive value of the plots is limited; at most the order-of-magnitude conductance for an untested solid could be estimated if the Debye temperature were known. Correlations of conductance with molecular weight, with $(\rho / \mathrm{m})^{2 / 3} \Theta_{D}^{-2}$ (from (5)), and with other parameters were also examined and found not to add 


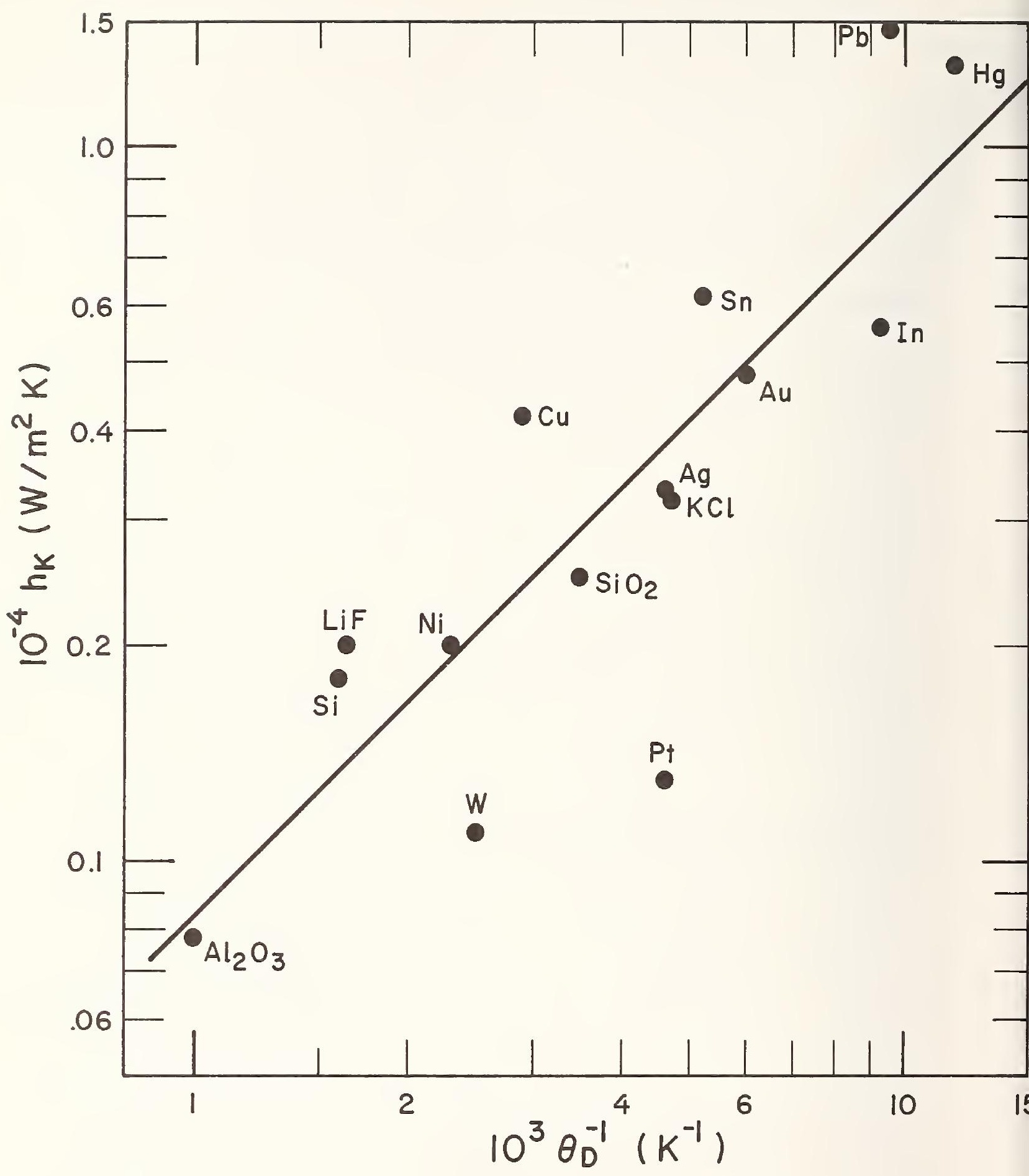

Figure 1. Kapitza conductance at $1.5 \mathrm{~K}$ - largest values observed for each solid are plotted. From Challis (19ó8). Ag data from Frederking (19ó8). 


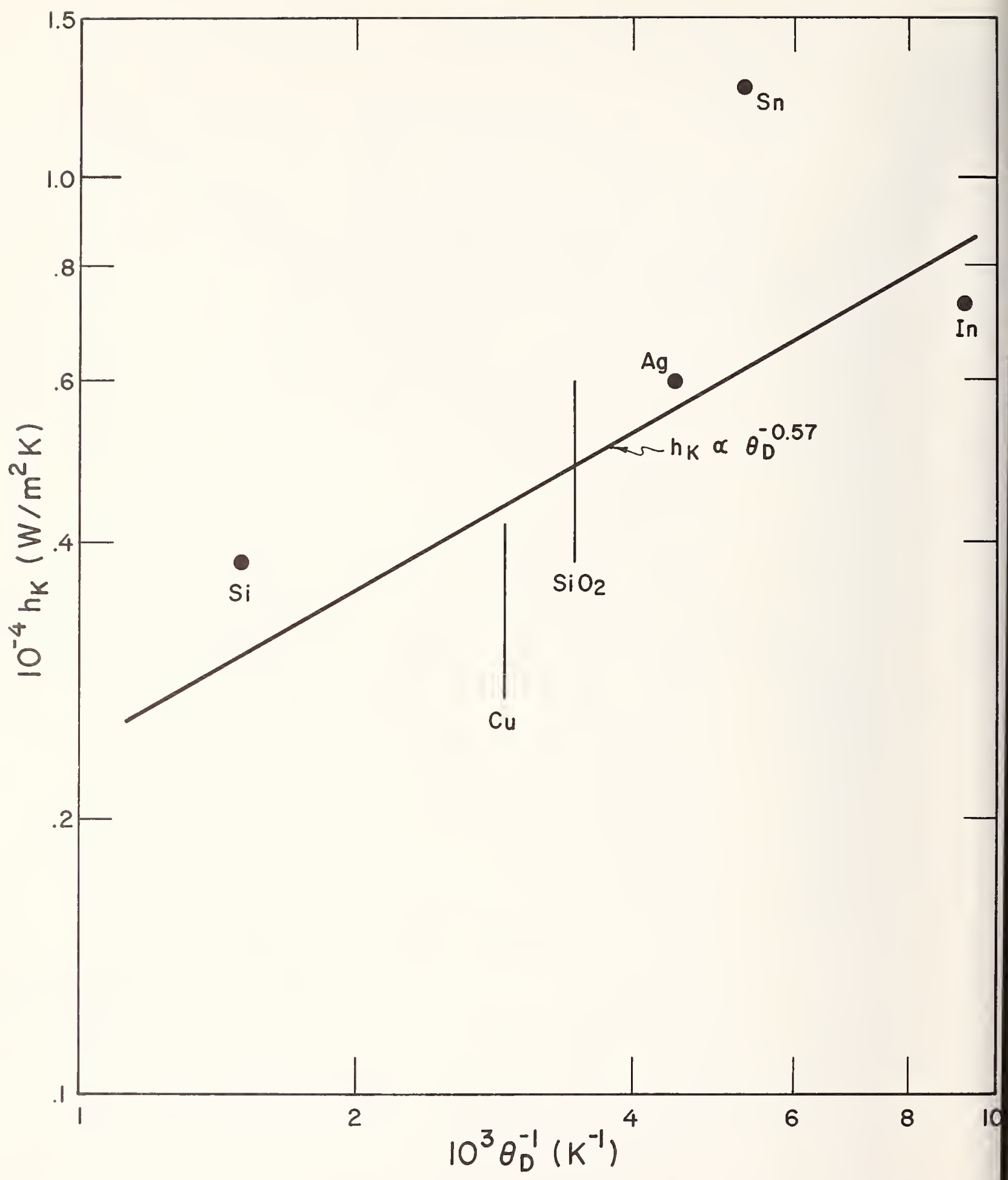

Figure 3. Kapitza conductance at $1.9 \mathrm{~K}$ for polished surfaces. In, Sn (Gittleman and Bozowski, 1962). Ag (Clement and Frederking, 1966). $\mathrm{SiO}_{2}$ (Challis, Dransfeld, and Wilks, 1961; Wey-Yen, 1962). Cu (Challis, Dransfeld, and Wilks, 1961; Challis, 1962). Si (Johnson and Little, 1963). 
anything to the presentation of data in figures 1 - 4. Measurements for other solids with clean surfaces would be helpful in developing correlations. Also the anomalous behavior of Sn and Pt indicated in figures 2 and 3, and the sharp decrease in conductance of $\mathrm{Ni}$ after electropolishing merit further investigation before such correlations are used to support new theories. A correlation recently reported for relatively clean surfaces (Fig. 1 of Hesser, Chapman, Chang, and Frederking, 1969) includes an error of a factor of 10 in the Pt data; hence the agreement with the data is actually poorer than indicated on the figure.

\section{c. Metals -- Effect of Electrons}

Experiments with metals can help answer questions about the way in which electrons participate in the heat transport processes at an interface. Since electron participation would involve magnetoresistive effects, these questions are of importance in high field applications of liquid helium cooling, as well as of theoretical interest. It is possible for the electrons in the metal to interact directly with the phonons of the liquid in two ways. The quantum-mechanical electron wave function has a finite probability density in the liquid, which dies away exponentially. This concept is also known as tunneling. Thus one mechanism is an interaction between tunneling electrons and phonons of the fluid. The second mechanism arises because the phonons of the liquid also penetrate somewhat into the metal, and can cause a density change of the charge near the surface and thus a modulation of the potential in 
which the electrons move. (Little, 1962 discusses these mechanisms in greater detail.) There have been several experiments related to the first mechanism. In an experiment by Gittleman and Bozowski (196́2), an ac electric field was applied at a platinum-helium interface by placing a high voltage probe in the liquid a short distance from the surface. If the electron wave functions from the metal were "leaking" into the liquid and coupling with the phonons of the liquid, ac modulation of the Kapitza conductance might have been observed. No modulation was seen, but the high work function of the platinum or a surface layer of adsorbed helium atoms might have inhibited the effect. In a study by Johnson and Little (196́3), a copper surface was milled under liquid helium to see if this would increase the penetration of electron wave functions into the liquid. It was concluded that the effect was either very small or masked by factors that were not understood. In addition, a calculation of such an effect by Bloch (see Johnson and Little, 1963) gives a temperature dependence of $\mathrm{T}^{5}$ instead of the approximate $\mathrm{T}^{3}$ dependence which is normally observed. Negative results were also obtained by Cheeke (1969) on a bare lead surface.

The second mechanism of electron-phonon coupling has been investigated by comparing the interface conductance of a sample in the superconducting and normal state. At temperatures well below the superconducting transition, according to current energy gap theories, most 
electrons cannot be easily excited and therefore do not interact with phonons or act as entropy carriers. If electron heat transport dominates phonon transport, as is often the case for a fairly pure metal, the thermal conductivity will be lower in the superconducting than in the normal state. Experiments with lead indicated a significant increase in Kapitza conductance when a superconducting sample was made normal by the application of a magnetic field (Challis, 1962; Gittleman and Bozowski, 1962 ; Barnes and Dillinger, 1963; Challis and Cheeke, 1965; Hesser, Chapman, Chang and Frederking, 1969). The ratio of normal to superconducting boundary conductance varied from about 3.0 to 1.35 for different samples. Recently, even higher ratios of 10 and 15 were reported for lead (Cheeke, 1969). Lower ratios were found for other metals: 1.3 for mercury (Neeper, Pearce, and Wasilik, 196́7), 1.1 for tin, and 1.06́ for indium (Gittleman and Bozowski, 196́2). The last two metals have a relatively small electron-phonon coupling. It is also possible that the tin and indium measurements were influenced by the superconducting transition in the solder which was used to mount the specimens (Neeper, Pearce and Wasilik, 196́7). No change in the Kapitza conductance of tin within $2 \%$ was reported by Wey-Yen (196́2). Decreases in conductance in the superconducting state at solid-solid interfaces have also been observed (see Frederking (1968) for further references). All of the superconducting-normal measurements discussed above were made by steady state methods on relatively thick samples, 
where the possibility of strain from differential thermal contraction in the mountings exists. Strain near the interface could cause a large decrease of the thermal conductance in the superconducting state (Rosenberg, 19ó3), which would result in a spuriously lower boundary conductance. Since the surfaces of the samples studied by Cheeke (1969) were machined under liquid helium,this mechanism was probably responsible for the very small conductances observed in the superconducting state. To avoid the problem of extrapolating thermal gradients in the bulk to the surface, measurements on the attenuation of second sound by a thin foil of lead were made more recently by Challis and Sherlock (1969), and these indicated no difference in the Kapitza conductance of the two states. Second sound consists of very low frequency thermal oscillations which propagate in helium II (see, e.g., Wilks, 1967), so this type of experiment actually measures the ac thermal conductance. When second sound measurements were made for copper by Brow and Osborne (1958), the observed conductance was significantly higher than that of any of the numerous steady state measurements, although no special surface preparation was carried out. The interpretation of the second sound measurements is somewhat complicated by the relationship of the phonon mean free path to the foil thickness (Challis and Sherlock, 196́9). Thus the correspondence between ac and steady state measurements is not clear. 
The superconducting studies of the Kapitza conductance seem to indicate that electron participation in the interface heat transport is small. However, some experiments with magnetic fields have shown sizeable effects. Field strengths of up to 2 tesla ( $20 \mathrm{kOe})$ have been employed. The first experiments with transverse fields on lead (Challis, $1961)$ showed an increase of about $1 \%$ in the conductance per $0.1 \mathrm{~T}$ change in magnetic field up to $0.4 \mathrm{~T}$, but the size of the experimental errors was about the same as the size of the effect. More such data were presented by the same author in a later paper (Challis, 196́2) in which an end effect correction to the bulk thermal resistivity was applied and the measurements were extended to $0.7 \mathrm{~T}$. Between 0.1 and $0.7 \mathrm{~T}$ there was a fairly constant increase of about $1 \%$ per $0.1 \mathrm{~T}$ in the Kapitza conductance. This is approximately in agreement with the increase observed with ac methods up to $2 \mathrm{~T}$ for a lead foil (Challis and Sherlock, 196́9). However, a considerable decrease in the effect was observed when the lead surface was cleaned of its oxide layer (Challis, 1964). For mercury, the change in conductance with increasing magnetic field was positive or negative for different samples (Neeper, Pearce and Wasilik, 1967), and was always less than $6 \%$ over $0.35 \mathrm{~T}$. An $0.4 \mathrm{~T}$ field had no observable effect on the Kapitza conductance of copper (Challis, Dransfeld and Wilks, 196́1). One explanation advanced for these effects of magnetic field upon conductance is that phonon scatter- 
ing is reduced when the electron energies are crowded into Landau levels, and further experiments on single crystal foils by Challis may validate this explanation (Challis and Sherlock, 1969). Since the Kapitza conductance could increase by as much as $100 \%$ in a $10 \mathrm{~T}$ field if the slope observed at low fields remains constant, further measurements at higher fields would also be of interest. 


\section{THEORIES OF KAPITZA CONDUCTANCE}

At present, there are no theories of the mechanism of thermal energy transfer at a solid-liquid interface which agree quantitatively with experiment. Nor have any theories been advanced which are useful in making qualitative predictions. The phonon radiation limit (5) is as good a guide to the temperature dependence and the relative magnitude of Kapitza conductance for a particular solid as are any of the theories to be discussed below. The following survey of theoretical work is presented primarily to give a background which may be of assistance in evaluating future theoretical papers.

Historically, because the existence of a solid-liquid interface resistance was discovered by Kapitza using helium II, the first theories hypothesized that superfluid properties were responsible for the observations. However, the fact that the resistance is appreciable only at low temperatures is explained by the thermodynamic considerations of Section 2. In fact, resistances of similar size have been observed with $\mathrm{He}^{3}$ (e.g., Lee and Fairbank, 1959), and also between two solids (see Syomi, Anderson and Holmström, 1968) in the same temperature range. There are no observable changes in the boundary conductance at $0.6 \mathrm{~K}$ where the spectrum of excitations in helium II exhibits a drastic change (Fairbank and Wilks, 1955). Neutron scattering experiments have shown that the short-wavelength thermal phonons 
of the liquid are not affected by the $\lambda$-point transition (Woods, 1965).

4. 1 Acoustic Mismatch

Khalatnikov $(1952,1965)$ has considered the various possible interactions of the phonons in the solid with the excitations in helium II. He concluded that above $2 \mathrm{~K}$, collision of helium phonons and rotons (see Wilks, 1967) with the solid would account for about $40 \%$ of the heat transfer, but that between 1 and $2 \mathrm{~K}$ the dominant effect would be the radiation of phonons by the oscillating solid surface. Assuming that the solid is essentially vibrating in free space because the density of liquid helium is so low, and that energy is rapidly removed from the surface, the calculation gives for the conductance for $\Delta \mathrm{T}<<\mathrm{T}$,

$$
h_{k}=\frac{16 \pi^{5}}{15} \frac{k^{4}}{h^{3} c_{t}^{3}} \frac{\rho_{\text {liq. }}{ }^{c_{\text {liq. }}}}{\rho_{\text {sol. }}}\left[F_{1}(\eta)+F_{2}(\eta)\right] \mathrm{T}^{3}
$$

where $\rho_{\text {liq. }}$ is the density and ${ }^{c}$ liq. is the velocity of sound in the liquid, $\rho_{\text {sol. }}$ is the density and $c_{t}$ is the velocity of transverse waves in the solid, and $\eta$ is the ratio of the velocities of longitudinal and transverse waves. $F_{1}$ and $F_{2}$ are of order unity, and have about the same value for most solids. $F_{1}$ refers to the allowed phonon transmission, and $F_{2}$ to the surface waves on the free surface of the solid. Energy transfer by $F_{2}$ should be negligible for a dielectric containing no impurities, or for a superconductor far below its transition temperature. 
The $\mathrm{T}^{3}$ dependence arises because the low temperature Debye approximation for the phonon energy density is used, as in the derivation of the phonon radiation limit. For comparison with this limit, equation (5) of Section 2, the Khalatnikov result may be expressed as

$$
h_{k}=\frac{2 \pi^{4}}{5} \frac{k^{2}}{\Theta_{D}^{2} \hbar}\left(\frac{3 N}{4 \pi}\right)^{2 / 3}\left[\frac{4}{3}\left(\frac{3 \eta^{3}}{2 \eta^{3}+1}\right)^{2 / 3}\left(F_{1}+F_{2}\right)\right] \frac{\rho_{\text {liq. }}{ }^{c_{\text {liq. }}} \mathrm{\rho}_{\text {sol. }} \mathrm{c}_{\mathrm{t}}}{} \mathrm{T}^{3} .
$$

Since $\eta$ is about 2 for most solids, the factor in brackets has the order of magnitude unity. The factor containing the ratio of acoustic impedances $\rho_{C}$ of the liquid and the solid reduces the predicted Khalatnikov conductance to two or more orders of magnitude below the radiation limit. Since the velocities of sound are so different, the momenta of phonons in the solid and liquid at the same temperature is very different, and few phonons will be transmitted because it is difficult to satisfy simultaneously the laws of conservation of momentum and energy for arbitrary angles of incidence.

Quantitative agreement of this theory with experiment is very poor, since for most solids the highest observed boundary conductances are less than one order of magnitude below the radiation limit (Tables II and III). Qualitatively, a dependence on $\Theta_{D}^{-3}$ should be observed when boundary conductances of different solids are compared at a given temperature. However, figures 1, 2, and 3 indicate that a dependence 
upon $\Theta_{D}^{-1}$ is more probable. Figure 5, a logarithmic plot of conductance at $1.9 \mathrm{~K}$ for clean, unstrained surfaces against $1 / \rho_{\mathrm{s}} \mathrm{c}_{\mathrm{t}}^{3}$, indicates that the observed conductances vary more nearly as $\left(1 / \rho_{s} c_{t}^{3}\right)^{0.38}$.

Since the Khalatnikov theory applies to an "ideal" interface, it is necessary to consider how it might be changed by the real interfaces for which data are available. Wey-Yen (1962) pointed out that according to an acoustic mismatch theory a layer of adsorbed gas or oxide on the surface would have little or no effect since the thickness of these layers is typically less than the wavelength of acoustic phonons. However, the thickness of the amorphous surface layer formed by the cold-working of a metal is comparable to the phonon wavelength of the solid. The elastic constants of such a layer are unknown, but Wey-Yen found that his data for cold-worked surfaces showed better agreement with the Khalatnikov theory if he assumed that $c_{t}$ was approximately constant. In this case, the conductance at a given temperature for cold-worked metals should vary as $1 / \rho_{s}$, but this relation is not confirmed when data of Wey-Yen are combined with data of other observers. With the exception of one case, Ni (Wey-Yen, 1962), removal of the cold-worked surface layer has always resulted in values of the conductance that are similar to or larger than the previous values, which makes agreement with the Khalatnikov theory worse.

The effect of surface roughness should also be considered. The effective area for acoustic transmission could be increased by only about 


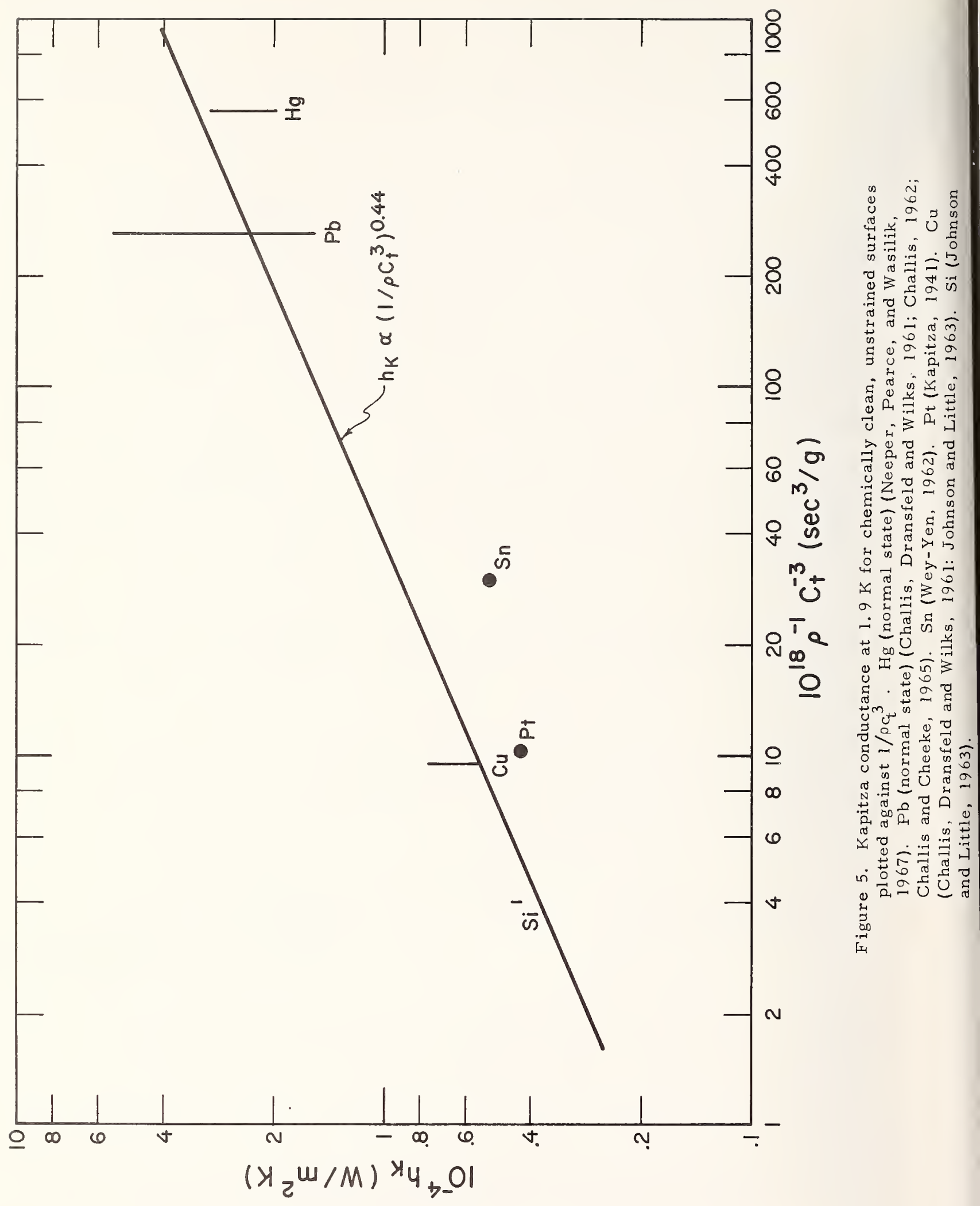


a factor of two by roughness (Challis, Dransfeld, and Wilks, 1961), which is not enough to improve the agreement significantly. Little (1961b) has shown that "microscopic" surface roughness which is less than the phonon mean free path will decrease the predicted Khalatnikov conductance by a small amount. If the roughness is greater than the phonon mean free path (Little, 1959), the temperature dependence of the conductance will be different from $\mathrm{T}^{3}$ because of the change with temperature of the wavelengths of excited phonons.

According to (6), it should be possible to change the conductance by a substantial percentage by pressurizing the liquid helium. However, several experiments showed that the change was much less than expected (Challis, Dransfeld, and Wilks, 1961; Wey-Yen, 1962; Anderson, Connolly and Wheatley, 1964). If the density of helium atoms near the solid surface is much higher than in the bulk liquid because of the van der Waals forces, the actual density at the interface does not vary as strongly with the applied pressure as does the density of the bulk liquid, and in addition, this denser layer should improve the acoustic matching and therefore the phonon transmission. A theory of these effects was developed by Challis, Dransfeld, and Wilks (1961). Although their procedure improves agreement with data, it still predicts conductance values that areorders of magnitude smaller than observed. Furthermore, a temperature dependence of $\mathrm{T}^{4.2}$ is predicted although most observations indicate that the exponent should be less than 3. 5. The difference 
in temperature dependence is due to the fact that the acoustic matching will depend upon phonon wavelength, and the number of phonons excited with a given wavelength varies with temperature. To evaluate the Challis, Dransfeld, and Wilks modification further, Johnson and Little (1963) calculated van der Waals interaction energies between helium atoms and a number of solids, making allowance for oxide layers and monolayers of adsorbed gases. They then found that even the predicted relative magnitudes for different solids failed to agree with their data, and that in some cases the disagreement was worse than for the unmodified Khalatnikov theory. There is also a question at present about whether the layer of atoms at the interface has a density near that of solid helium (Steele, 1956; Manchester, 1967). A calculation by Singh and Band (1955) showed that the repulsive energy between such densely packed helium atoms would be so much greater than the van der Waals attractive energy that the difference in free energy would not be made up by any reasonable value for the entropy of the film. Manchester has reviewed the experimental evidence and shown that it does not necessarily lead to a densely packed, immobile surface layer of atoms.

An attempt to consider a somewhat different transition region between solid and liquid was made by Abbe (1968). In this case, penetration of atoms from the liquid into the solid is postulated (Abbe, 1967). Using kinetic theory and the Debye approximation for the specific heat 
Abbe obtained a conductance varying as $\mathrm{T}^{3}$ with an adjustable parameter in the expression. With this adjustable parameter, Abbe was able to fit some experimental results almost exactly, but at present it is not possible to obtain a priori values of the parameter, or to apply the theory to explain the different results for the same solid.

Experimental attempts to improve impedance matching were made by Whelan and Osborne (1969). Films of barium stearate of various thicknesses which were deposited on gold, copper, and sapphire improved the conductance. According to the numerical results, which were quoted only for gold, even the highest conductance obtained in this series of experiments is slightly less than that obtained earlier by Johnson and Little (196́3) for a bare gold surface. Whelan and Osborne point out that there are several uncertainties in the interpretation of these results.

The conclusion is that acoustic mismatch theories do not succeed in interpreting the experimental observations, although the reason for this failure is unclear. It is sometimes stated that the acoustic mismatch theory as extended by Little (1959) has been reasonably successful in explaining the interface conductances between two solids (Frederking, 1968; Pollack, 1969). Actually, the acoustic mismatch between two solids is relatively small, so the theory predicts conductances that are typically about one-half of the phonon radiation limit. Because of experimental problems in making a good thermal contact between two solids, it is dif- 
ficult to decide whether this or an acoustic mismatch causes the measured conductances to fall slightly below the phonon radiation limit (Von Gutfeld, Nethercot and Armstrong, 196́6).

4.2. Electron Mechanisms and Surface Disturbances

Electron transport accounts for most of the thermal conduction in a pure metal at low temperatures, so the Khalatnikov theory, which is based upon phonon transmission at an interface, actually implies that a further resistance will arise from the necessity of transferring the electron energy to the phonons at the interface. Direct energy exchange between the electrons and the vibrating surface is not considered. However, Little (196 la) has pointed out that the large number of phonons from the liquid reflected at the interface may produce a spatially varying disturbance of the lattice ions which would extend approximately $1 / 10$ th of a wavelength into the bulk solid. Then energy may be rescattered from the surface layer of ions by imperfections in the solid. For single crystal silicon, however, no significant difference in Kapitza conductance was found between a highly perfect crystal and one with a dislocation density one hundred times greater (Johnson and Little, 1963).

In a metal, the surface disturbance changes the ion charge density which provides a mechanism of electron-phonon interaction which could increase the interface heat transport beyond that due to phonon transmission. Calculations of this effect have been made by Little (196́la) 
and by Andreev (1962a, 1962b), using a free electron model of the metal. A discussion and comparison of the two calculations is given by Challis and Cheeke (1968). The most important feature of the calculations is that both result in an expression similar to (ó) of the Khalatnikov theory, except that $F_{1}$ and $F_{2}$ are replaced by expressions depending upon electron parameters. (In the limit of strong coupling of the electrons to the surface waves, the Andreev calculation equals $F_{2}$ ) These new expressions are still of order of magnitude unity, so this approach does not increase the theoretical conductance to a point where agreement with experiment is possible. Although approximations were used in carrying out these calculations, it seems unlikely that orders of magnitude would be changed in a more exact calculation. Little (19óla) originally stated that the lack of agreement with experiment might be due to these approximations, but in a later paper (Johnson and Little, 196́3) he concluded that the mechanism was inadequate as an explanation of the data. Qualitatively, the theory predicts a value of about 2.4 for the maximum ratio of conductances in the normal and superconducting state. This is in accord with the early results for lead, and was regarded as a success of the electron-mechanism theory until recent work cast doubt upon the lead experiments (Challis and Sherlock, 1969). The theories did not make any quantitative predictions of the effects of large magnetic fields, though the possibility of a de Haas-van Alphen type of oscillatory behavior (for 
single crystals) was discussed (Little, 19óla).

4.3. Thermal Accommodation

Although it is often asserted that Kapitza discovered interface resistance in 1941, the existence of a discontinuity of temperature between a solid surface and a gas was experimentally demonstrated in 1898 , by Smoluchowski (1898). This gas-solid temperature discontinuity is ascribed to incomplete transfer of energy by the collisions of gas atoms at temperature $\mathrm{T}_{\mathrm{g}}$ with atoms of the solid at a temperature $\mathrm{T}_{\mathrm{S}^{\circ}}$ If the energy with which the gas molecules rebound from the wall is considered to correspond to an intermediate temperature $\mathrm{T}^{\prime}$, the effect can be defined by the thermal accommodation coefficient

$$
\alpha=\frac{T^{\prime}-T_{g}}{T_{S}-T_{g}} \text {. }
$$

A more rigorous definition of $\alpha$ may be given in terms of distribution functions of molecular velocities (Hurlbut, 1966). By definition, $a$ is independent of pressure, and this independence has been verified by careful experiments in which the solid surface composition does not vary with pressure (Wachman, 1962). For cases of limited heat input in which certain assumptions of kinetic theory are valid (Harris, 196́7), the temperature jump between the solid and gas is given by

$$
\Delta \mathrm{T}=\mathrm{T}_{\mathrm{S}}-\mathrm{T}_{\mathrm{g}}=\frac{\mathrm{Q}}{\mathrm{P}}\left(\frac{\pi \mathrm{M} \mathrm{T}_{\mathrm{g}}}{2 \mathrm{R}}\right)^{1 / 2} \frac{2-\alpha}{2 \alpha}
$$


where $P$ is the pressure, $M$ the molecular weight of the gas, and $Q=-K(d T / d r)$, with $K$ the gas thermal conductivity.

For gases, the accommodation coefficient concept has been so influential that nearly all analyses of gas-solid surface interactions have been expressed in terms of $\alpha$ and similar parameters. At very low pressures and/or high temperatures, of course, the mean free path of the gas molecules is too large to permit the propagation of phonon waves from the solid, or equivalently, the acoustic mismatch is very great. Whether the acoustic mismatch approach or the energy accommodation approach is most relevant for a liquid-solid interface seems unclear at present. Johnson and Little (1963) suggested that, in view of the failures of the various modifications of the acoustic mismatch theory, an entirely different mechanism of adsorption and desorption of helium atoms on the solid surface should perhaps be considered. Such a mechanism is related to thermal accommodation processes, although the exact equivalence may be questioned (Wachman, 1962). In a recent experiment by Mate and Sawyer (1968), the thermal resistance between gaseous helium and copper was measured in the range of 1.5 to $4.2 \mathrm{~K}$. At these temperatures, several layers of helium atoms will be adsorbed on the solid surface, and the authors interpreted their results as due to an energy accommodation resistance between the bulk gas and the adsorbed atoms in series with a Kapitza resistance between the adsorbed atoms and the copper. 
Equation (9) was used to separate the accommodation term from the total measured resistance by selecting a value of $\alpha$ which would remove the pressure dependence for the remaining data. The temperature dependence and magnitude of the Kapitza resistance thus derived was similar to that measured by other workers between liquid helium and an untreated copper surface. Since most of the accommodation coefficients in the literature were measured for solids with one or more layers of adsorbed gas, it is difficult in general to make this separation of the data.

In later, more extensive experiments with an improved apparatus (Mate and Sawyer, 1969), the Kapitza resistances of both the liquid and vapor phases of $\mathrm{He}^{3}$ and $\mathrm{He}^{4}$ were measured between 1.5 and $4.5 \mathrm{~K}$. After the calculated contribution from the accommodation term is subtracted for the gas phases, the resistances for gaseous and liquid $\mathrm{He}^{3}$ and $\mathrm{He}^{4}$ above the lambda point are similar. Below the lambda transition, the measured Kapitza resistances are anomalously low. The accommodation term becomes negligible at the higher pressures used in these experiments, since the authors use an $\alpha$ of order unity in (9). 
If experimental results for the accommodation coefficient of helium gas on various surfaces were available in the low temperature range, it would be interesting to compare the data with Kapitza conductances. However, such data do not exist. One conclusion that may be drawn from data at higher temperatures, most of it for gases other than helium, is that $\alpha$ approaches 1 , that is, energy exchange improves, as the surface becomes more contaminated with foreign gases. This seems opposite to the effect of surface contamination observed for Kapitza conductance, but actually the same type of contamination is probably not being observed, for this consists of a few monolayers of gas in the accommodation coefficient measurements in contrast to oxide or other chemically different layers in the Kapitza measurements. Gas monolayers are generally present in the latter measurements, but their effect has not been systematically investigated. A result of a simple classical analysis is that $\alpha$ should be inversely proportional to the molecular weight of the atoms in the solid for light gases. This relation appears to hold approximately for helium, but careful investigations have only been made for two solids (Thomas, 1966). The Kapitza conductance, however, seems to increase as $M$ increases. 
It is also interesting to compare the temperature dependence of $\alpha$ to that of the Kapitza conductance. Early experiments (Roberts, 1932) indicated that $\alpha$ for helium on a tungsten surface decreased markedly between room temperature and $80 \mathrm{~K}$, and a one-dimensional theory (perpendicular incidence of molecule) based on the Debye approximation for the solid and a Morse potential for the helium-solid interaction could be fitted to these experimental points (Devonshire, 1937). More recent measurements (Thomas and Schofield, 1955; Thomas, 1966) on cleaner tungsten surfaces gave a smaller value for $\alpha$, and showed that it decreased less rapidly in this temperature range. Below $50 \mathrm{~K}$, $\alpha$ started to increase rather rapidly. This increase is in sharp constrast with the earlier theory of Devonshire, in which $\alpha$ decreased roughly as $\mathrm{T}^{3}$ at low temperatures, as the lattice vibrations and the Kapitza conductance do. A rigorous, general theory of accommodation coefficients does not exist at present (Hurlbut, 1966; Goodman, 1968). A recent semi-empirical expression of Goodman and Wachman (1967) which fits the newer data for clean surfaces is

$\alpha(\mathrm{T})=1-\exp \left(-\mathrm{T}_{0} / \mathrm{T}\right)+(2.4 \mu /(1+\mu))^{2} \tanh \left[\frac{7.1(\mathrm{MT})^{1 / 2} \mathrm{~b}(1+\mu)^{2}}{\mathrm{~m} \Theta_{\mathrm{D}}}\right] \exp \left(-\mathrm{T}_{0} / \mathrm{T}\right)$ 
The mass of the gas atoms is $M$, that of the solid atoms is $m$, $\mu=\mathrm{M} / \mathrm{m}, \Theta_{\mathrm{D}}$ is the Debye temperature, and $\mathrm{b}$ is a Morse potential parameter. $\mathrm{T}_{\mathrm{O}}$ is a measure of the temperature at which $\alpha$ begins to depart from unity. It is higher for gases with higher heats of adsorption. For helium, a very low value of $T_{0}$ of a few tenths of a degree brings (10) into agreement with the new data for a tungsten surface mentioned above.

Because of the lack of both a general theory and relevant experimental data, an explanation of thermal resistance at a liquid-solid interface in terms of energy accommodation does not seem profitable at present. Nevertheless, in interpreting Kapitza conductance data, it may be useful to keep such concepts in mind. For example, Johnson and Little (1963) carried out an experiment in which the Kapitza conductance was measured before and after a copper surface was milled under. liquid helium. Contrary to expectations based upon the Challis, Dransfeld, and Wilks modification of the acoustic mismatch theory, the conductance was reduced after machining. Presumably the surface before milling had one or more layers of $\mathrm{N}_{2}, \mathrm{O}_{2}$ and $\mathrm{H}_{2} \mathrm{O}$ physically adsorbed, which could be expected to improve the energy accomodation of impinging molecules according to accommodation coefficient experiments. While there were other important factors in this experiment, such as room temperature recrystallization of the work-hardened surface, this example 
does indicate how the predicted effects of surface treatment can depend upon the model assumed for energy exchange.

\section{INTERFACE CONDUCTANCE WHEN $\triangle \mathrm{T} \sim \mathrm{T}$}

When the interface temperature difference $\Delta \mathrm{T}$ rises above the range where $\Delta \mathrm{T}<<\mathrm{T}$, properties of the bulk liquid increasingly determine the heat transfer. Three fairly distinct regions of behavior may be described which depend upon both the magnitude of the heat input and properties of the solid surface. Initially, the data obeys a Kapitza relation such as (4) expanded to include higher powers of $\Delta \mathrm{T} / \mathrm{T}$. When the surface temperature becomes approximately equal to $\mathrm{T}_{\lambda}$, deviations occur and the slope of $d h / d(\Delta T)$ decreases slightly (fig. 6). At a surface temperature approximately a degree higher than $\mathrm{T}_{\lambda}$, a maximum heat transfer rate $\mathrm{q}^{*}$ is reached, after which the liquid adjacent to the wall is vaporized, and behavior similar to film boiling for ordinary liquids is observed. $\mathrm{q}^{*}$ is about $10 \mathrm{~kW} / \mathrm{m}^{2}$ for a flat surface.

\section{1. Kapitza Region}

In deriving (4) for the net energy flux across the interface, only terms to first order in $\Delta \mathrm{T} / \mathrm{T}$ were kept in the expansion $(\mathrm{T}+\Delta \mathrm{T})^{4}-\mathrm{T}^{4}$. Thus as $\Delta \mathrm{T}$ increases, initially one would expect the conductivity to follow the form:

$$
h^{\prime}=h_{k}\left[1+(3 / 2)(\Delta T / T)+(\Delta T / T)^{2}+(1 / 4)(\Delta T / T)^{3}\right]
$$


where $h_{k}$ is the function of $T$ defined in (4). In figure 6, which shows data of Clement and Frederking (1965) for a polished silver surface, the dashed lines correspond to (11). The data begin to deviate for this equa tion because the surface reaches the $\lambda$-transition temperature, before the highest order terms become effective. Similar behavior for $h^{\prime}$ was found with a Ni-Fe film heater (Holdredge and McFadden, 1966; Madsen and McFadden, 1968). In the Kapitza region, the effect of increasing the pressure on the bath up to at least 1 atm. is not noticeable (Madsen and McFadden, 1968). There are also no observable effects of the depth of immersion of the heater upon the heat transfer (Irey, McFadden, and Madsen, 1965). The total heat flux across a surface of a given geometry is simply proportional to its surface area, as was the case in the limit $\Delta \mathrm{T} \rightarrow 0$. The only effect of the bath temperature, $\mathrm{T}_{\mathrm{b}}$, is to determine at what $\Delta \mathrm{T}$ deviations from (11) will begin to occur, since this $\Delta \mathrm{T}$ is approximately equal to $T_{\lambda}-T_{b}$. Hence, in this region, the observed effects are essentially still determined by only the properties of the solid surface.

\section{2. Pre-Film Boiling Region}

After the temperature at the solid surface becomes approximately equal to $\mathrm{T}_{\lambda}$, the observed behavior is determined by a combination of liquid and solid properties. Geometrical effects, such as the depth of immersion of a test specimen compared to the diameter of the specimen, 


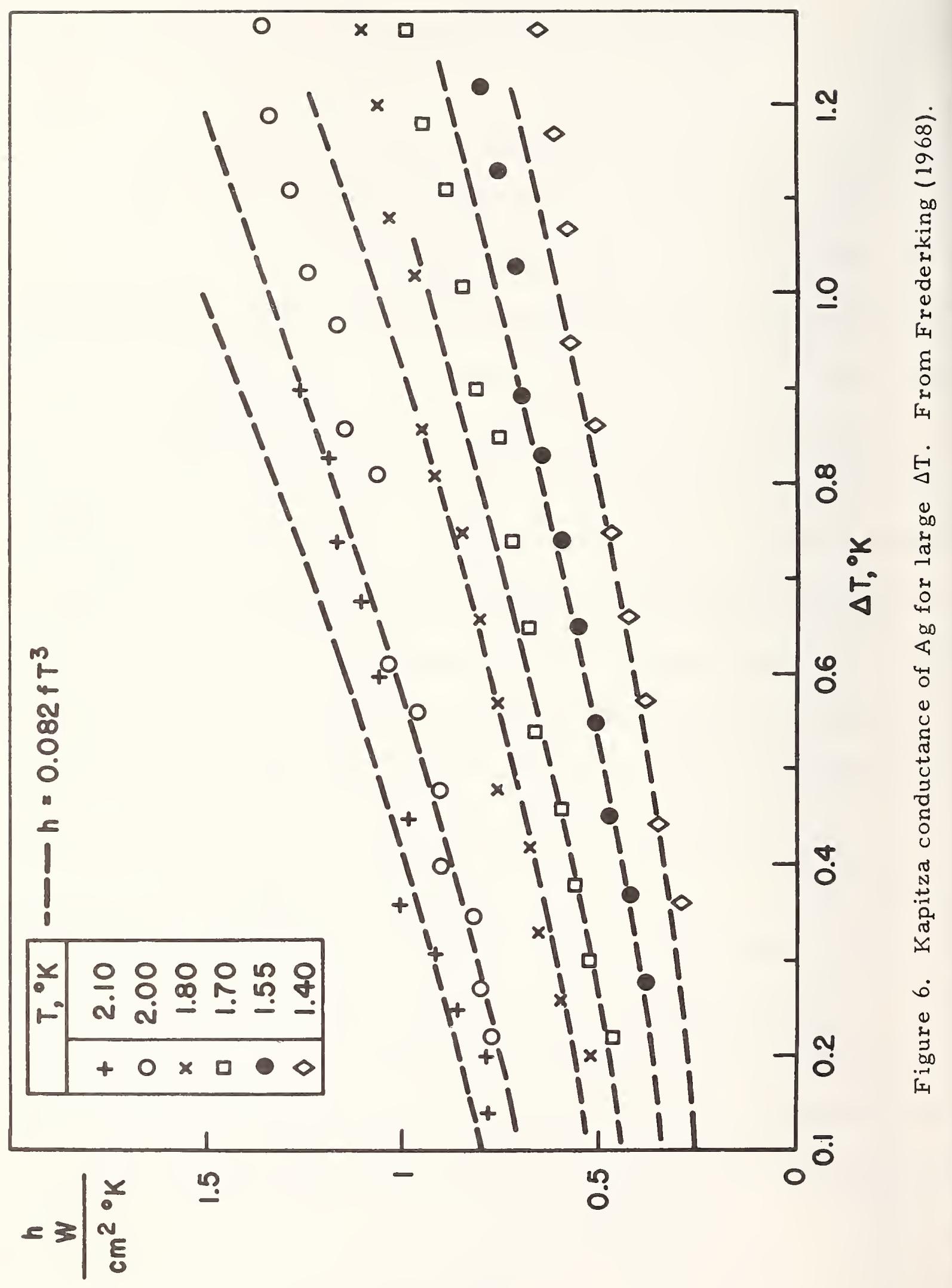


and to the diameter of the dewar, become important. Pressure and temperature of the bath now have noticeable effects on the heat transferred. Studies with an interferometer by Peshkov (1958) show that the density of a layer of liquid adjacent to the surface is different from the bulk value, and that the boundary between the regions of different fluid density is sharp. A peak heat flux, $\mathrm{q}^{*}$, is reached before vaporization of the layer adjacent to the surface occurs. The available data seem to indicate that $\mathrm{q}^{*}$ is entirely independent of the solid surface properties (Frederking, 1968). However, the corresponding temperature discontinuity, $\Delta \mathrm{T}^{*}$, is related to the properties of the solid, as will be discussed further in Section 5. 3 .

Not much data are available on the effects related to the liquid for $\Delta \mathrm{T}$ less than $\Delta \mathrm{T}^{*}$. Madsen and McFadden (1968) found that the heat transfer was roughly doubled if the pressure over the bath was increased from the saturated value to approximately 1 atm. Andronikashvili and Mirskaia (1956) reported that the heat transfer at 8 atm. was increased by a factor of 10 to 20 over the saturated vapor pressure values. Increasing the depth of the liquid above the heated surface also increased the heat transfer (Holdredge and McFadden, 1966). The heat flux per unit area for two cylinders was observed to be greater for the cylinder of smaller diameter in this $\Delta \mathrm{T}$ region, but these observed fluxes were not reproducible from run to run (Holdredge and McFadden, 1966). 


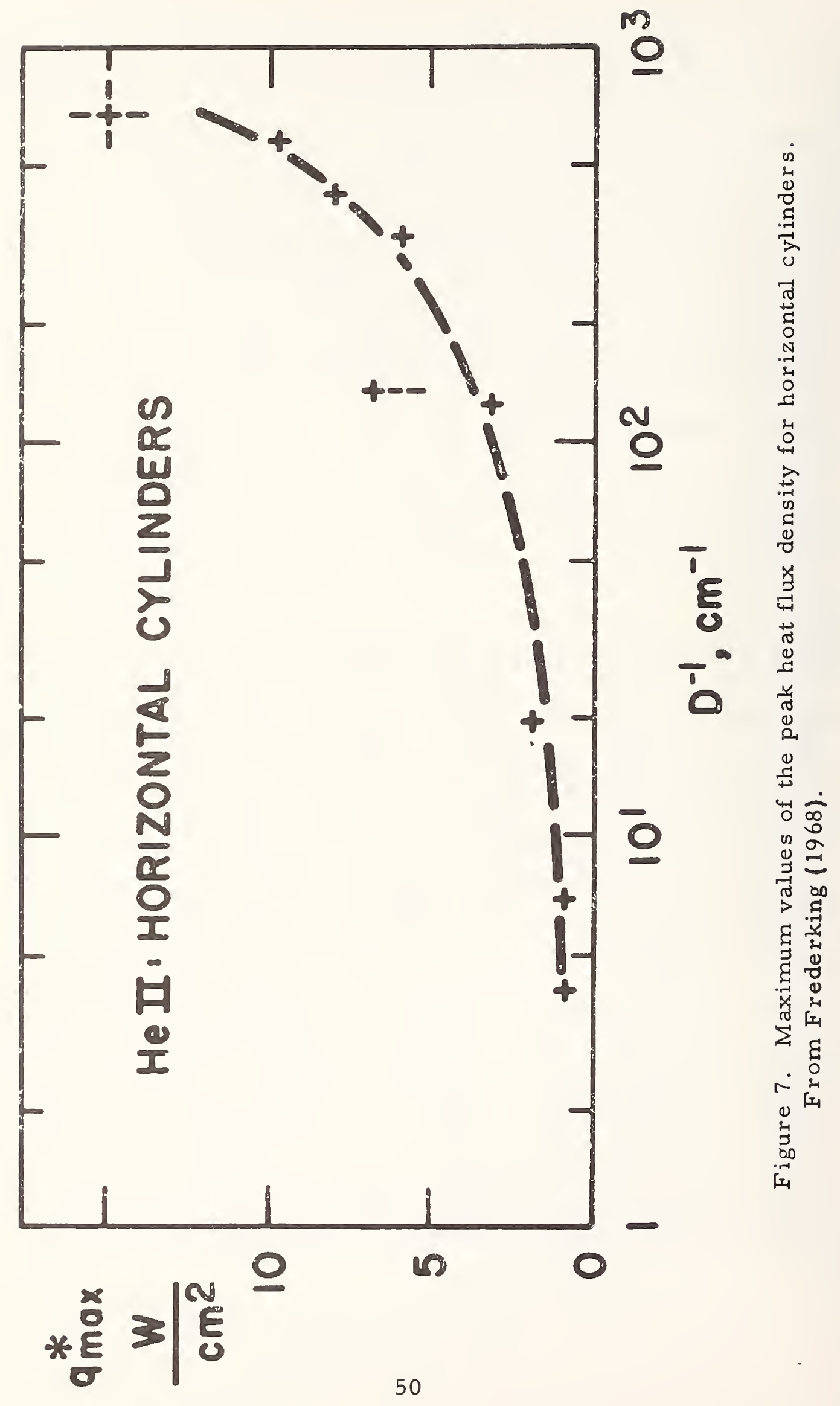


5. 3. $\mathrm{q}^{*}-$ Maximum Heat Flux

Considerable information is available about the parameters which affect the magnitude of $\mathrm{q}^{*}$, the maximum heat flux. This quantity varies roughly from 10 to $150 \mathrm{~kW} / \mathrm{m}^{2}$. The effects of geometrical configuration bath temperature, and pressure on $\mathrm{q}^{*}$ will be considered first, and then the effect of the solid surface on $\Delta T^{*}$ will be discussed. Frederking (1968) presents a more detailed discussion. Although $\mathrm{q}^{*}$ for flow in a capillary tube has been investigated by Rorschach and Romberg (1957), most studies have concerned heat dissipation from a horizontal cylinder placed in a helium bath. The diameters have ranged in size from thin wires to infinity, that is, a flat surface. Figure 7, reproduced from the review paper by Frederking (1968), shows that the highest $q^{*}$ values are obtained for fine wires, and that a limiting value of about $10 \mathrm{~kW} / \mathrm{m}^{2}$ would be expected for a flat surface at about $1.9 \mathrm{~K}$. This is in agreement with experimental results for flat surfaces (Clement and Frederking, 1965; Lyon, 1965), and the Kutateladze correlation followed by ordinary fluids (Brentari, Giarratano and Smith, 1965). The scatter of the points in figure 7 and the extrapolations and corrections used to get the points are discussed by Frederking (1968).

Since the data presented in figure 7 represents different solids, the fact that almost all of the data fall on the same curve would seem to indicate that the properties of the solid are of lesser importance. The 
extent of influence of these properties could be better gauged from studies in which the surface characteristics of a sample were varied, while other parameters were kept constant. Lyon (1969) has observed significant effects upon the peak heat flux density when a platinum surface is coated with a thin layer of organic material or water.

As noted above, the test dewar diameter and depth of immersion of the heater also affect $\mathrm{q}^{*}$. The effect of immersion depth has been investigated for wire heaters of 17 to $81 \mu$ diameter in an infinitely large pool between $T_{\lambda}$ and $2.00 \mathrm{~K}$ by Frederking and Haben (196́8). Lemieux and Leonard (1968) have reported data on the effect of immersion depth upon heat transfer for a fine wire over a larger temperature range. The effect of immersion depth decreased in importance as $\mathrm{T} \rightarrow 0 \mathrm{~K}$ and $\mathrm{T} \rightarrow \mathrm{T}_{\lambda} \cdot A$ few other scattered measurements of the immersion depth effect are given in the literature (Frederking, 196́1; Irey, McFadden and Madsen, 1965), but not enough data are available to derive an analytic form for $\mathrm{q}^{*}$ as a function of the geometric parameters. The experimentally observed variation of $\mathrm{q}^{*}$ with temperature below the $\lambda$ point is shown in figure 8 . A maximum occurs at about 1.9 K. Other types of experiments also show a maximum in heat transport at about $1.9 \mathrm{~K}$, and it appears that this behavior is explicable entirely 


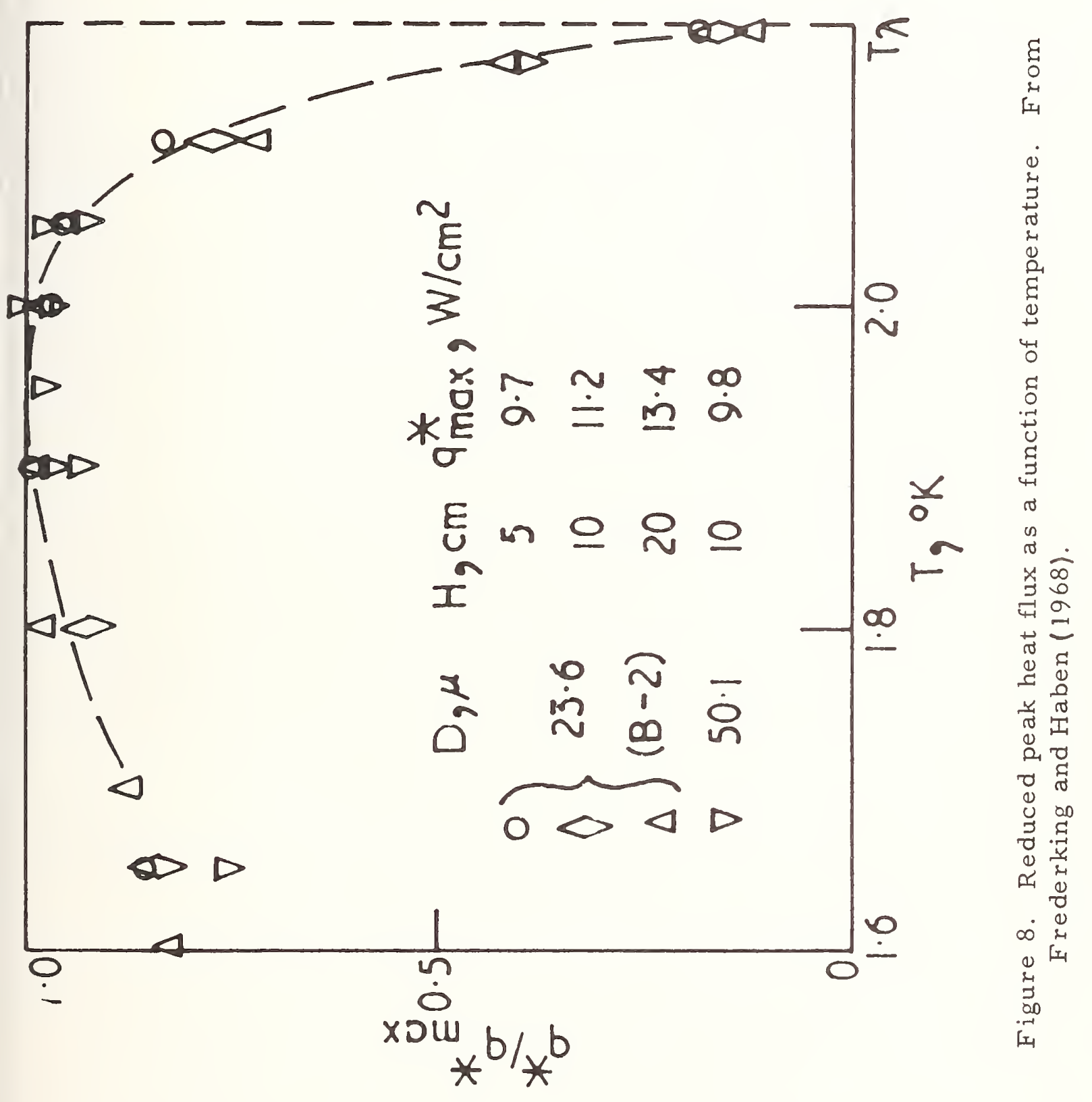


on the basis of liquid properties. If the two-fluid model of helium II superfluidity is invoked to explain this temperature dependence, the Gorter-Mellink model for mutual friction between the normal and superfluid components of helium II gives

$$
q=\rho_{S} \operatorname{ST}\left(S / A \rho_{n}\right)^{1 / 3}(\nabla T)^{1 / 3}
$$

Equation (12) is discussed further by Arp (1970). It has a maximum at $\mathrm{T} \cong 1.9 \mathrm{~K}$, as illustrated in figure 3 of Arp (1970). Another expression with similar temperature dependence has also been proposed (Clement and Frederking, 1965; Frederking, 196́8).

The dependence of $\mathrm{q}^{*}$ on pressures up to about one atm. is shown in figure 9, for the case of horizontal and vertical thin wires. The solid lines in the figure are correlations obtained for ordinary liquids. These expressions are exceeded for helium II, at least for fine wires.

In contrast with $\mathrm{q}^{*}$, which seems to be essentially hydrodynamically limited, $\Delta \mathrm{T}^{*}$ appears to be correlated with the observed Kapitza resistance, from the small amount of evidence available so far. As a functio 


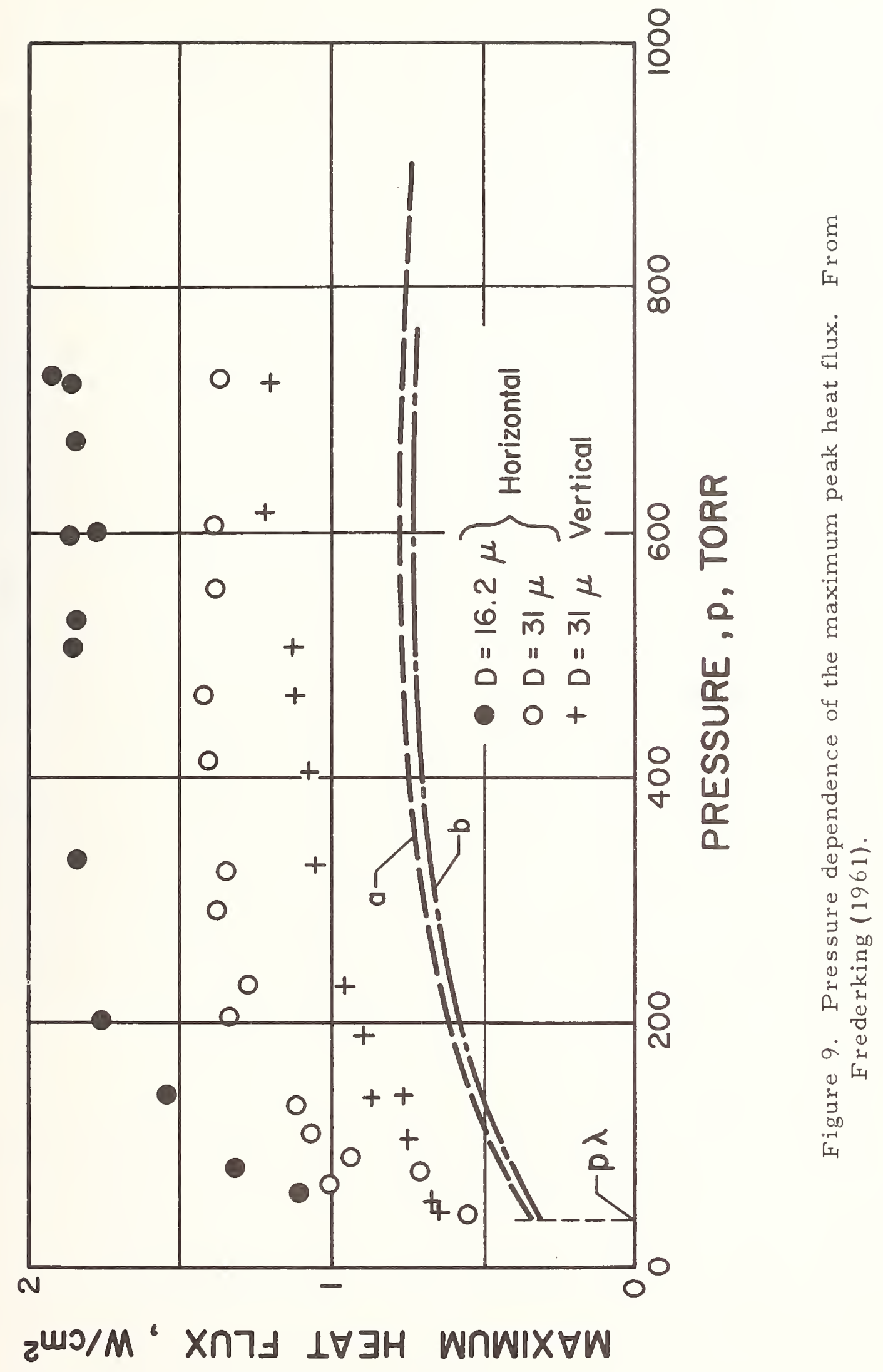


of temperature, $\Delta \mathrm{T}^{*}$ appears to have about the same dependence as $\mathrm{q}^{*}$. Both these trends are indicated in figure 10, taken from Frederking (1968). Since the Ni-Fe alloy had a higher Kapitza conductance than the silver, and the observed peak heat flux $q^{*}$ was about the same for both, $\Delta \mathrm{T}^{*}=\mathrm{q}^{*} / \mathrm{h}^{*}$ is expected to be smaller for the alloy. The information presented earlier in this section can be used to estimate $\mathrm{q}^{*}$ for a particular geometry, pressure and temperature. (Equation (12) may be scaled to give the temperature dependence.) If $h(T)$ can be estimated using (11) and low $\Delta \mathrm{T}$ measurements from information in Section 2, $\Delta \mathrm{T}^{*}$ can be found to a first approximation. Where solid-liquid interface data are not available, upper and lower bounds for $\Delta \mathrm{T}^{*}$ can be obtained from simple considerations suggested by Frederking (1968). These give

$$
\left(\mathrm{T}_{\lambda}-\mathrm{T}_{\mathrm{b}}\right) \leq \Delta \mathrm{T}^{*} \leq \Delta \mathrm{T}^{*}{ }_{\text {He I }}+\left(\mathrm{T}_{\lambda}-\mathrm{T}_{\mathrm{b}}\right)
$$

where $T_{b}$ is the bath temperature, and $\Delta T^{*}{ }_{H e}$ the peak nucleate boiling temperature difference, which appears to be less than about $2 \mathrm{~K}$ from available He I experimental data.

5. 4. Film Boiling

After $T^{*}$ is reached, the heated surface is surrounded by a film of vapor, and the conductance across the boundary decreases by a factor of about a hundred. Since Kapitza conductance is proportional to the third power of the temperature, it rapidly ceases to be a limiting factor 


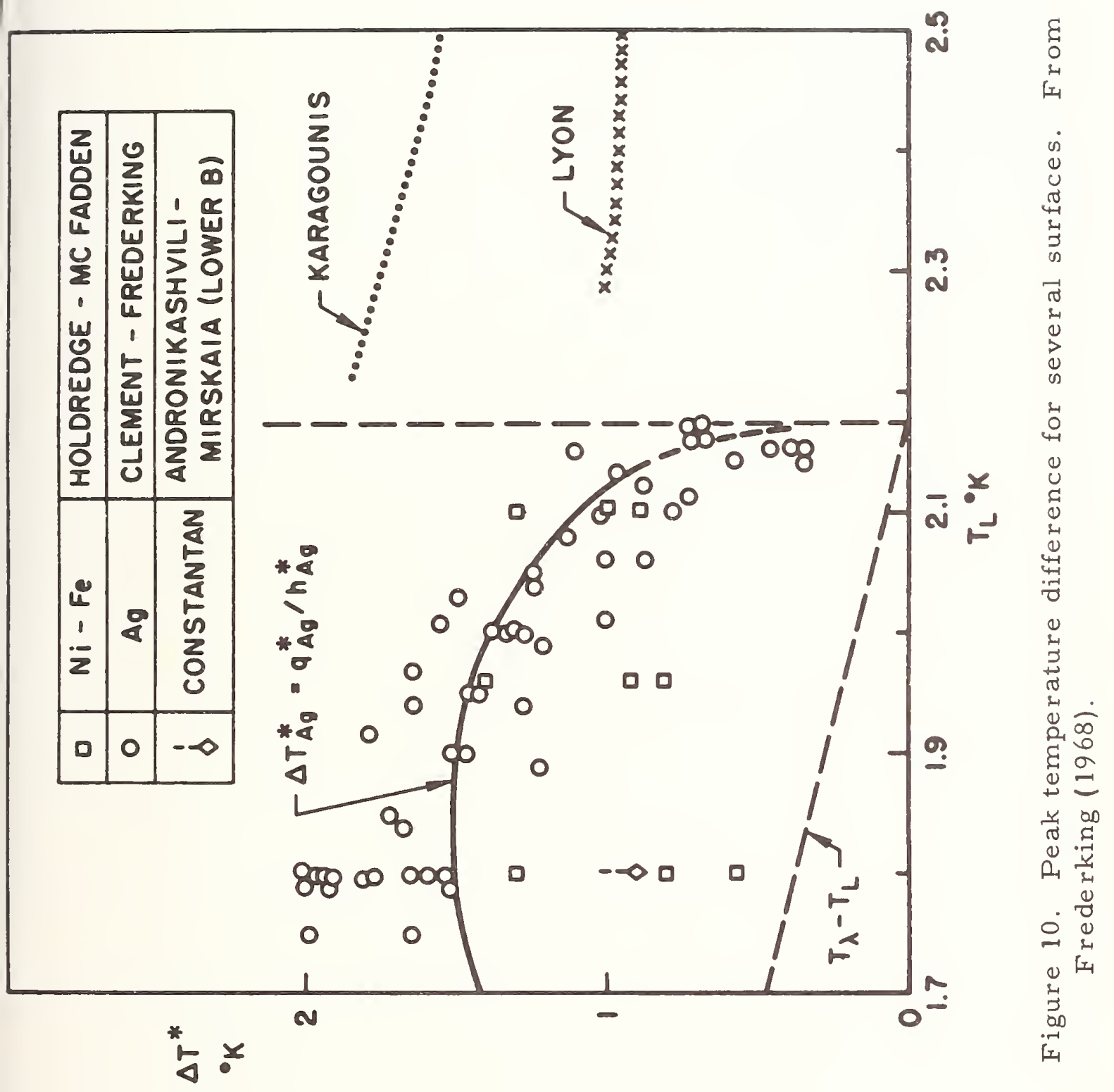


in this $\Delta T$ range. Hence this region is outside the scope of the paper, and will be treated very sketchily with references to fuller discussions elsewhere. A good brief discussion is found in Frederking (1968).

At very high $\Delta \mathrm{T}$, film boiling correlations for or dinary liquids were in approximate agreement with the experimental data of Holdredge and McFadden (1966). Frederking (1961) has also investigated the extent to which He II film boiling data can be described by conventional correlations. He presents data on film boiling for thin wires which indicates the dependence of the heat transfer upon wire diameter, pressure, and depth of immersion. No discontinuity in film heat conductance $h$ at the $\lambda$ point was observed, but $d h / d(\Delta T)$ is discontinuous because of these effects. Recently, a theory which applies to lower $\Delta \mathrm{T}$ values has appeared (Rivers and McFadden, 1966); at present the validity of the model hypothesized in the calculations has not been fully checked experimentally, though agreement over a small range of experimental parameters is satisfactory. It should also be noted that the presence or absence of noise associated with the breakup of a smooth gas film over the surface affects the heat transfer in this $\Delta T$ range considerably (Frederking, 1968; Lemieux and Leonard, 1968). 


\section{SUMMARY}

The thermal barrier at the interface between a solid and liquid helium II will be much larger than the thermal impedance of the bulk liquid in most cases. Hence a better understanding of Kapitza conductance is essential to the further development of the technology of heat transfer to helium II. The phonon radiation limit, based on thermodynamic considerations, is closely approached by the non-metallic crystals which have been studied, and by the two metals, copper and lead, with which some work has been done to bring surface conditions closer to the ideal of a simple termination of the bulk. This possibility of approaching the theoretical limit merits further investigation, but the parameters which determine the conductance of practical interfaces also remain to be identified. These parameters are unknown at present because the specific mechanism of energy exchange at the surface has not been established. The phonon transmission process on which the acoustic mismatch theory is based has been most used in attempts to explain the experimental data, but both the original theory of Khalatnikov and its various modifications predict conductances that are one or more orders of magnitude below those actually observed. A possible alternative process is energy exchange between the atoms of the fluid and those of the solid by adsorptiondesorption. This process is related to the thermal accommodation of gases on solid surfaces, but accommodation coefficient calculations also have not 
achieved agreement with experiment at present. The question of whether the conduction electrons in metals exchange energy directly with the phonons of the liquid is also unclear because of conflicting experimental evidence and because the theories developed for such processes are in order of magnitude disagreement with experiment.

A theoretical solution of the interface conductance problem would be of great intrinsic interest as well as of considerable practical assistance in the development of helium II technology. For present design problems, an order-of-magnitude estimate for a chemically cleaned or polished metal surface can be made from figures 1 through 3 if the Kapitza conductance of the metal has not been measured. If the surface is not cleaned or polished, allowance for a conductance of as much as a factor of 10 less should be made. Judging from the limited information now available on non-metals, the phonon radiation limit, (5), can give an approximation to within a factor of about 3 of the conductance if the Debye temperature is known or can be estimated. (See Blackman, 1955 for further Debye temperature information.) Even if the conductance of the material under consideration has been previously measured, considerable caution should be exercised in applying the data from Table I, since it has been shown that conductances of different samples can vary by about an order of magnitude. The condition of the surface for which the measurements were made should be noted. If heat inputs are large enough 
that the $\Delta \mathrm{T} \ll \mathrm{T}$ limit is exceeded, heat transfer mechanisms in the bulk liquid are also important, and the considerations of Section 5 must also be taken into account. 


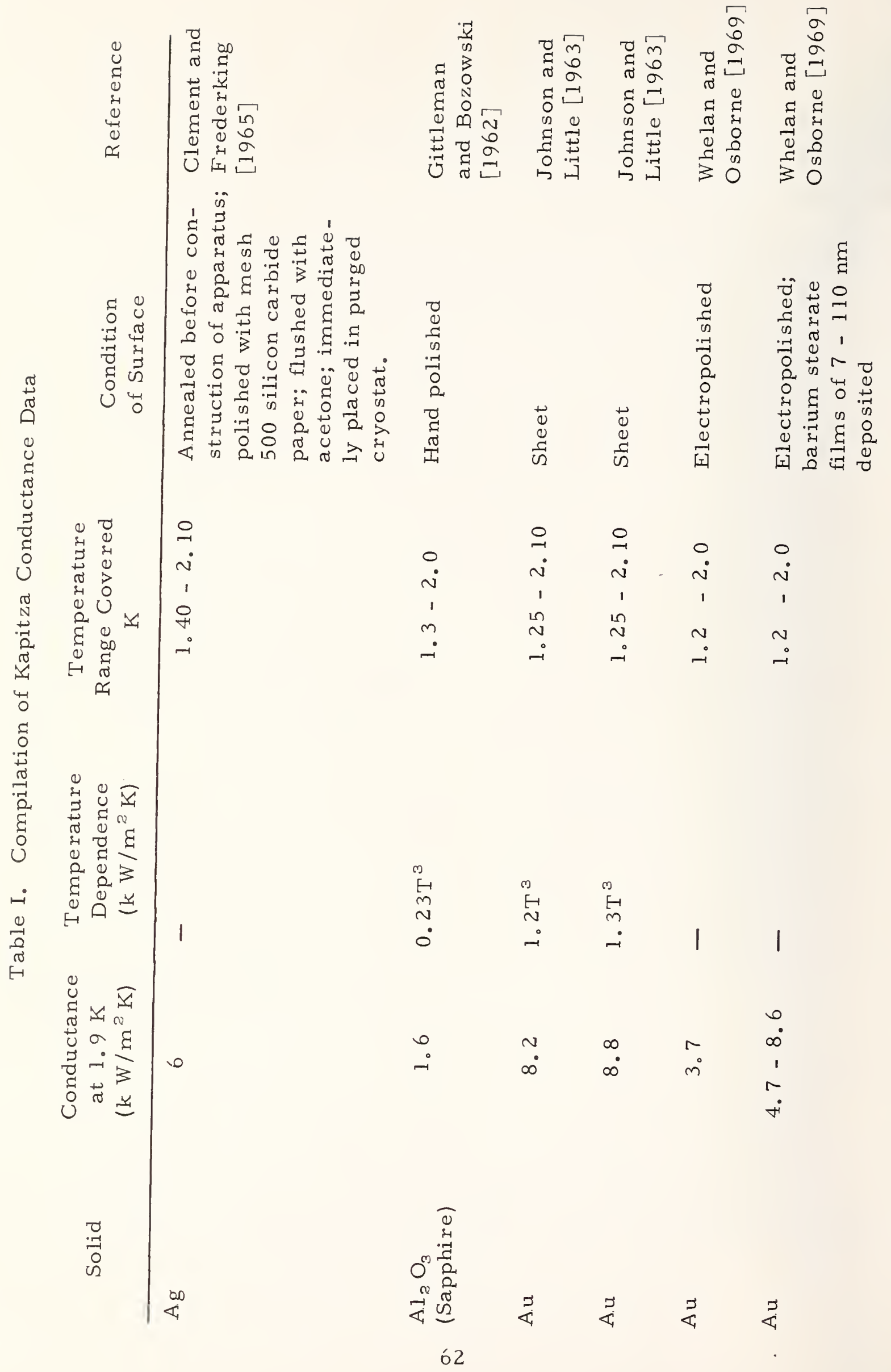




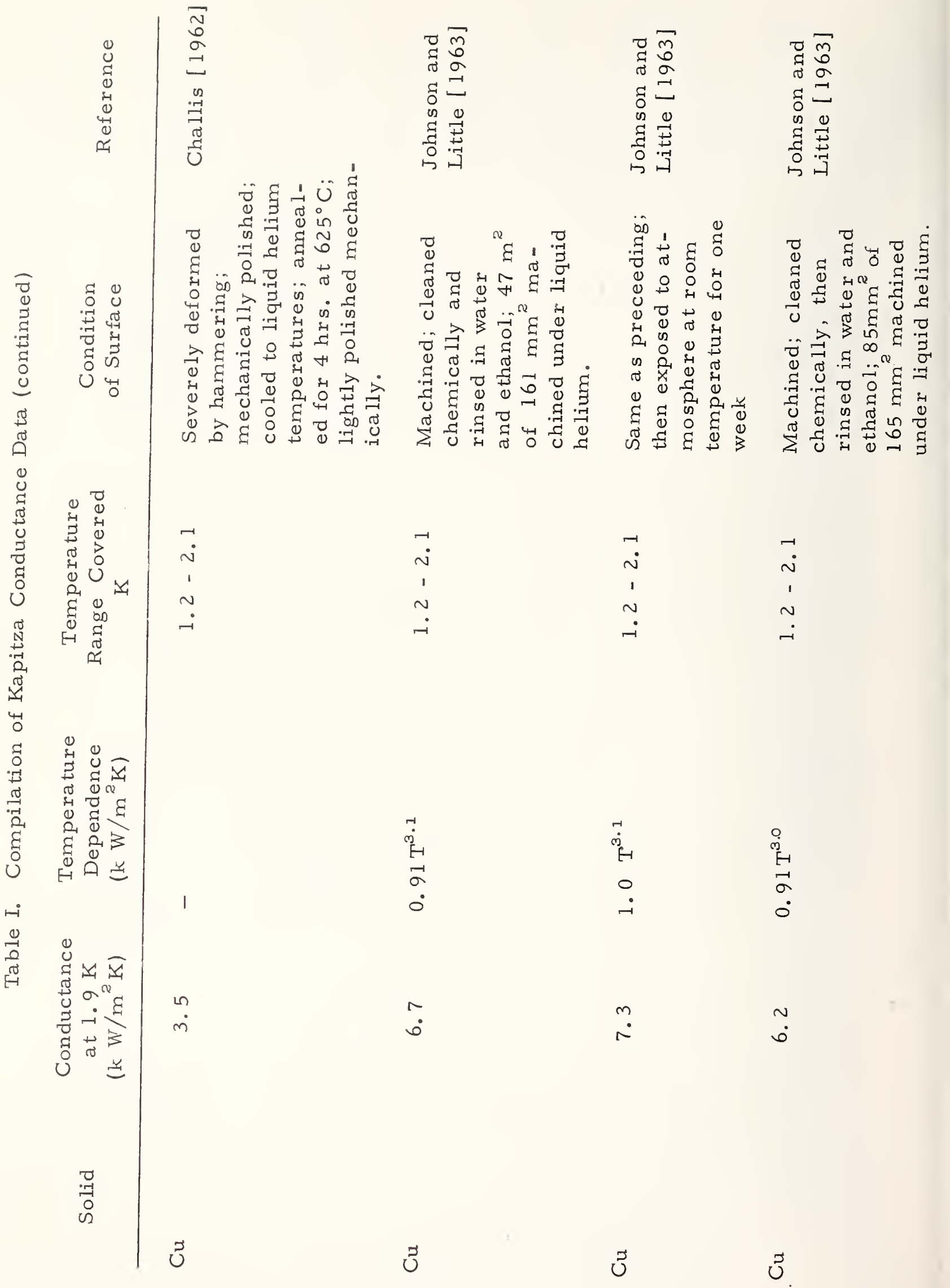




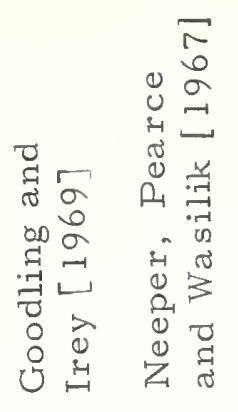

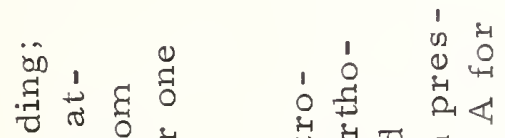

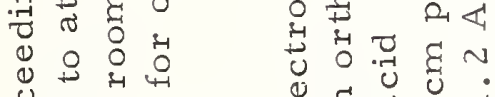

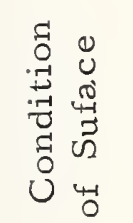

仓

ข

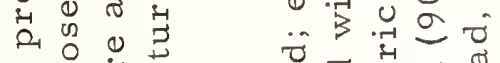

थ

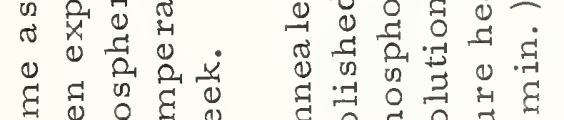

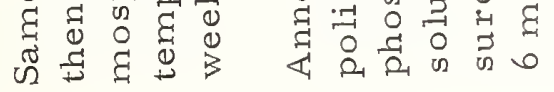

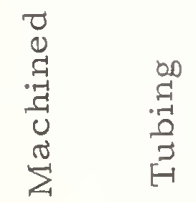

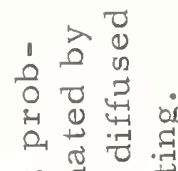

ن.

舶

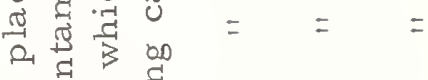

Ũ

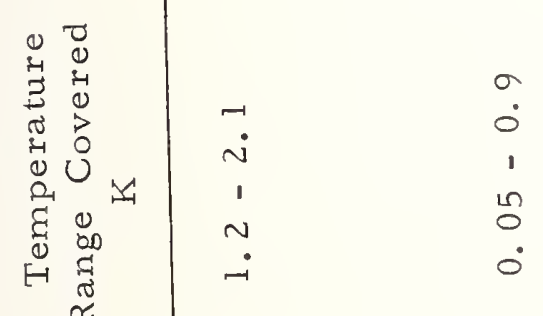

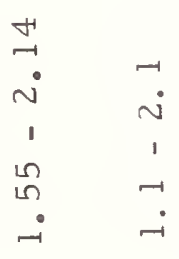

$\underbrace{0}_{3}$

\& गु द्व

$\stackrel{0}{\mathrm{C}} \mathrm{d}$

द્व:

$\stackrel{\infty}{i}$

$\begin{array}{ll}\stackrel{n}{n} & m \\ 0 & \tilde{n} \\ 0 & 0 \\ 0 & 0\end{array}$

ב

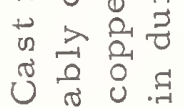

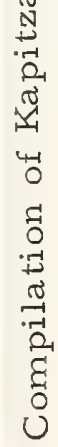

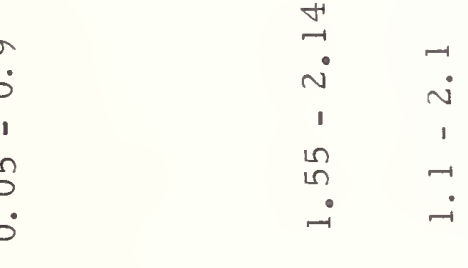

f-

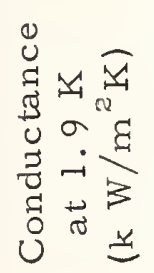

$\stackrel{0}{0} \quad \dot{4}$

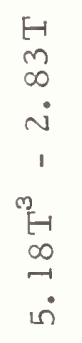

$\begin{array}{ccc}H & H & H \\ 0 & n & n \\ \sigma & m & m \\ \dot{j} & -i & \text { i } \\ 1 & 1 & 1\end{array}$

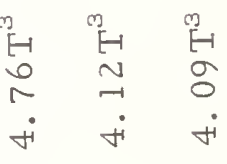

$\stackrel{1}{n}$

$\stackrel{N}{\circ}$

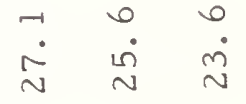

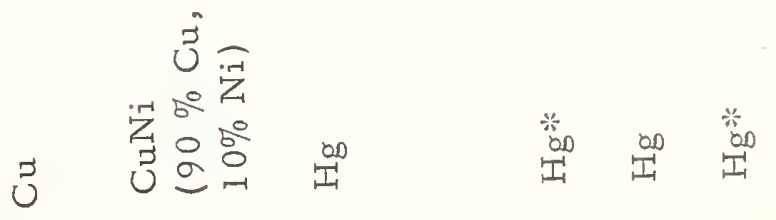

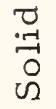

uี

క 


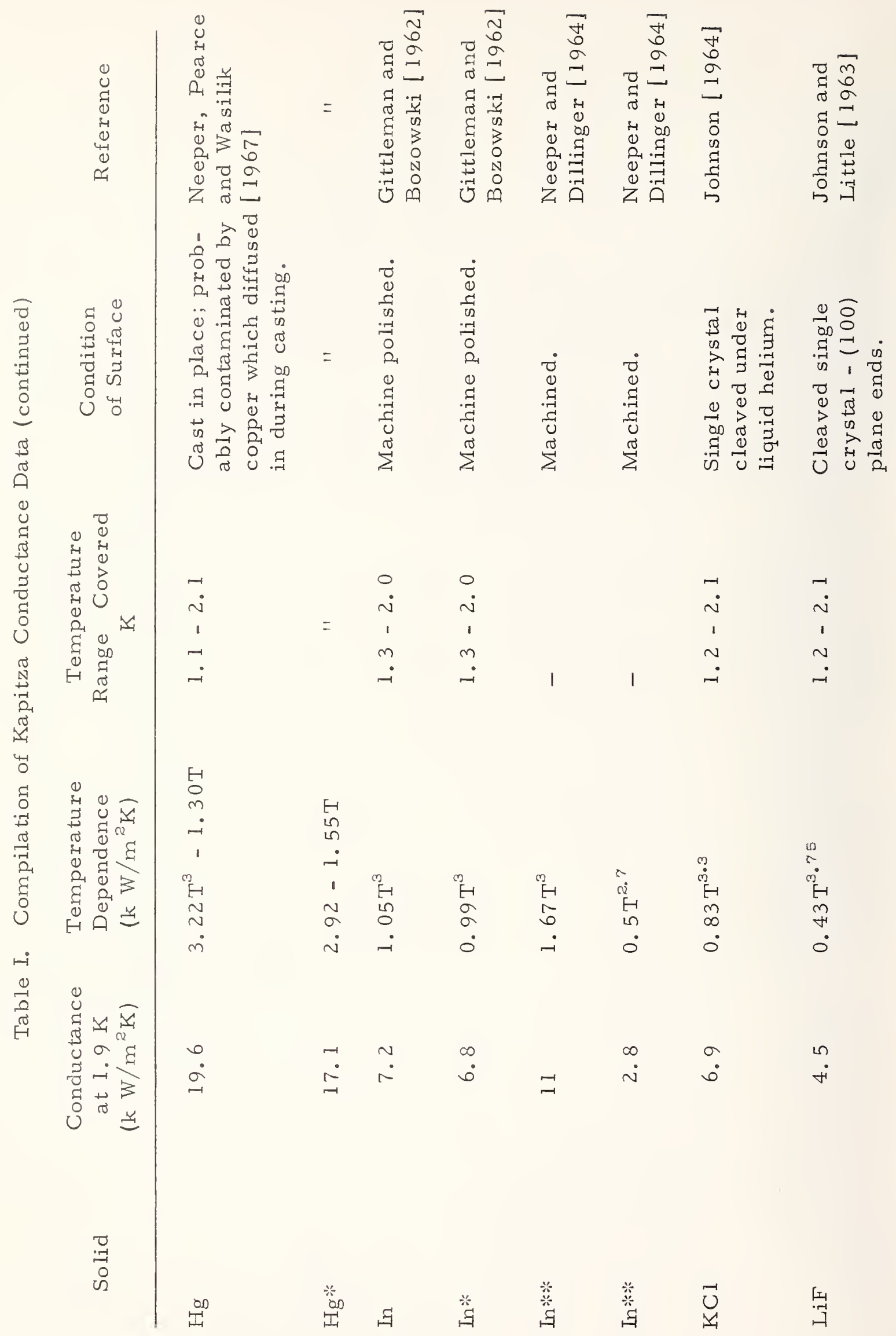




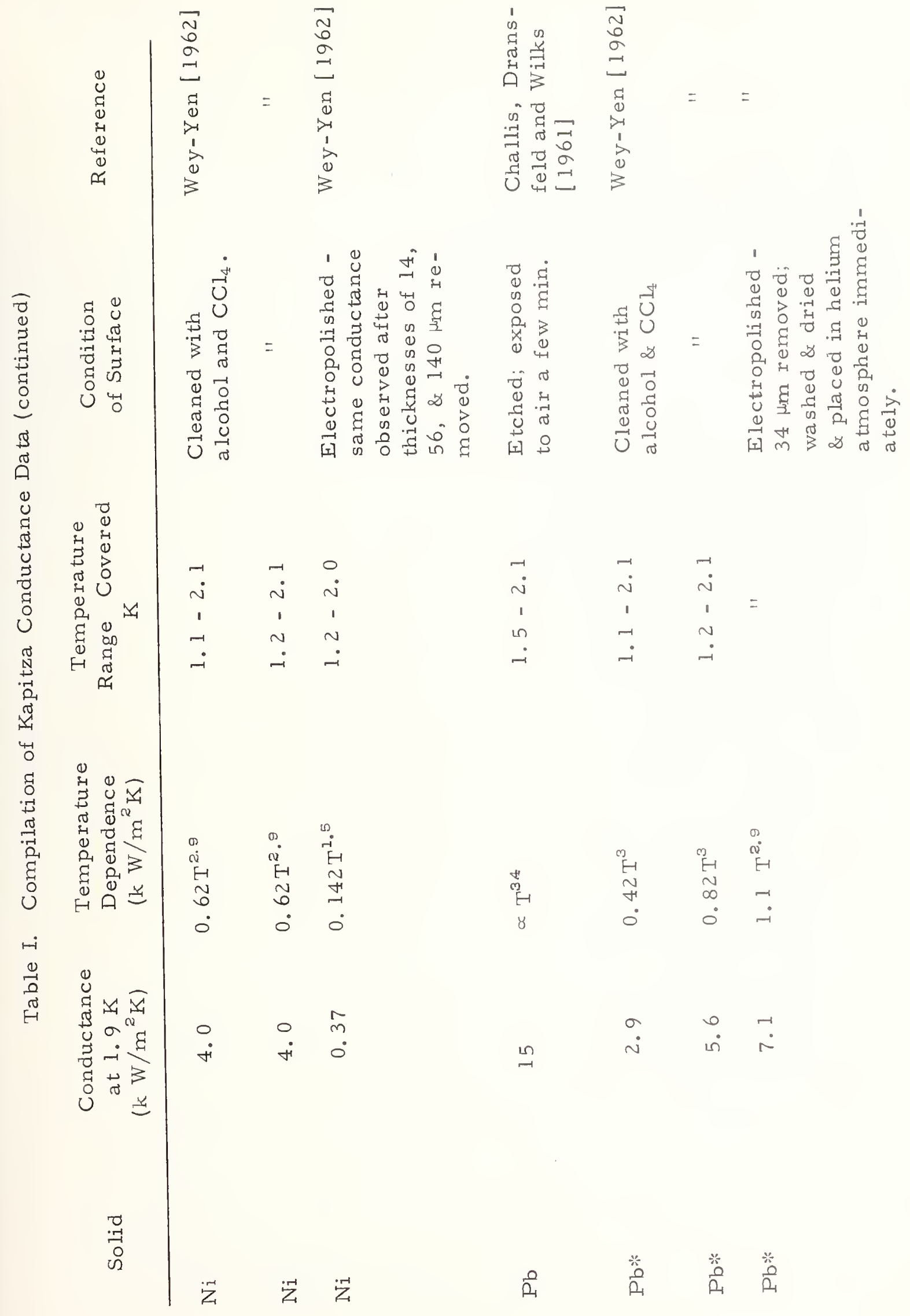




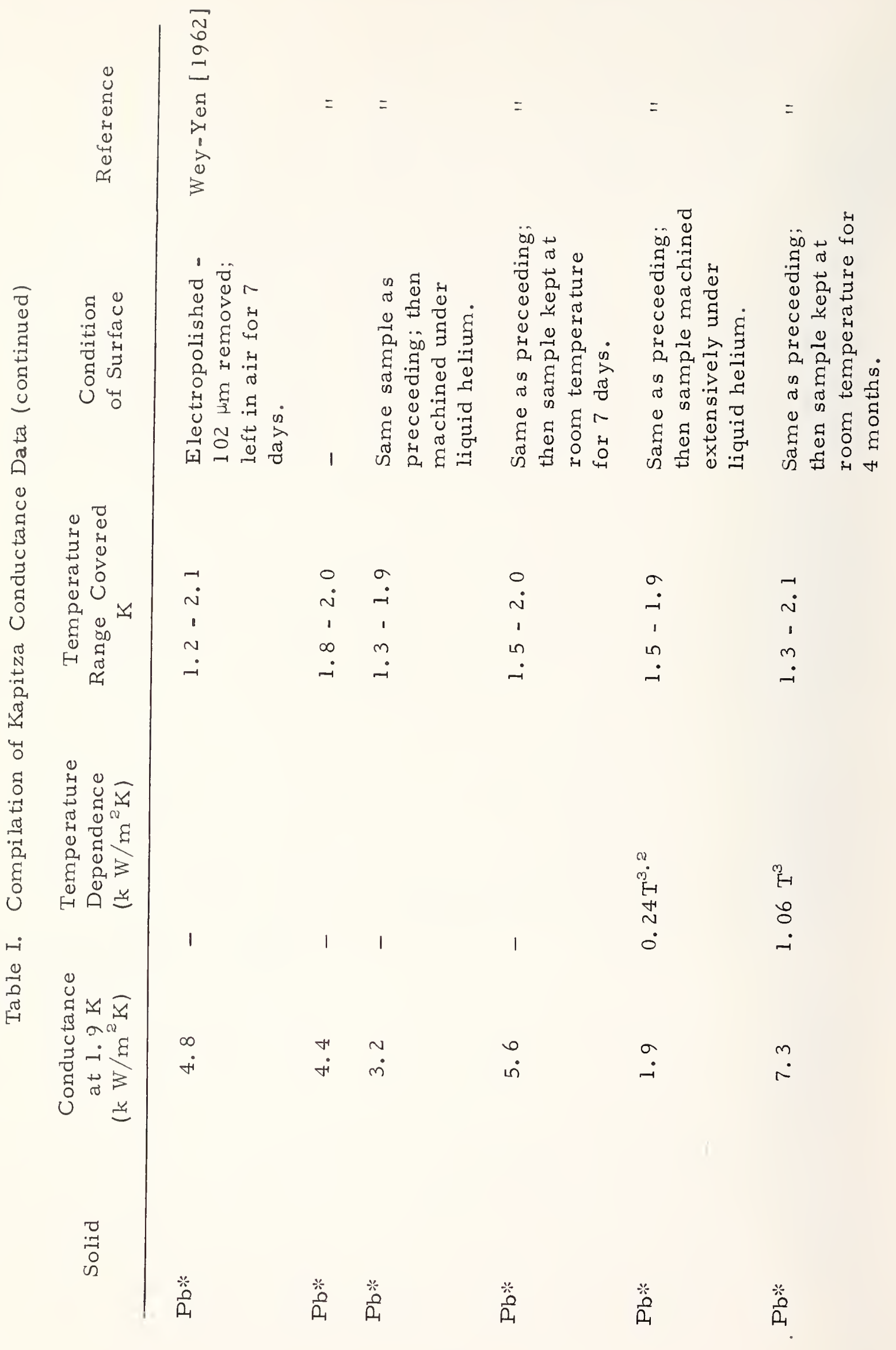




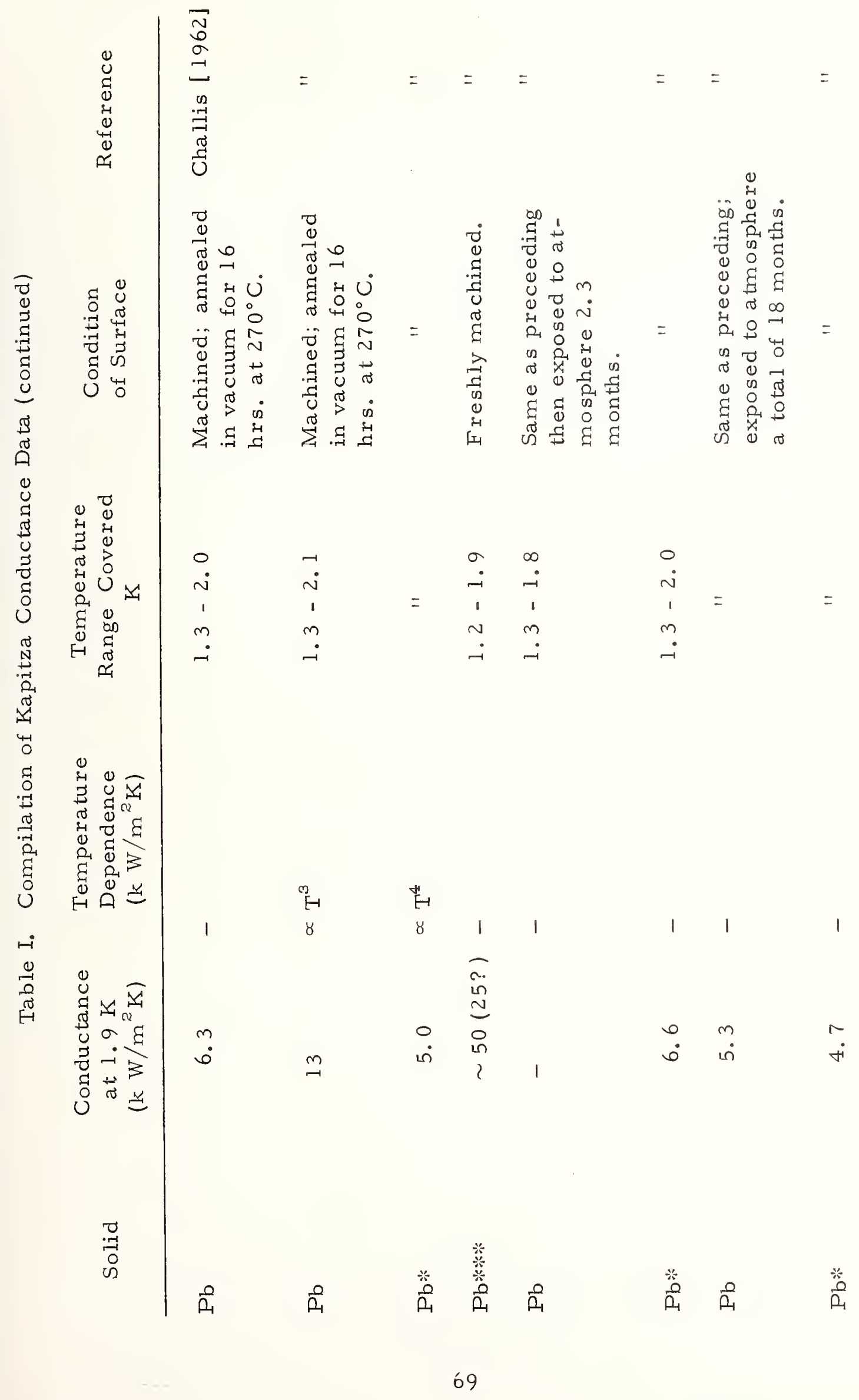




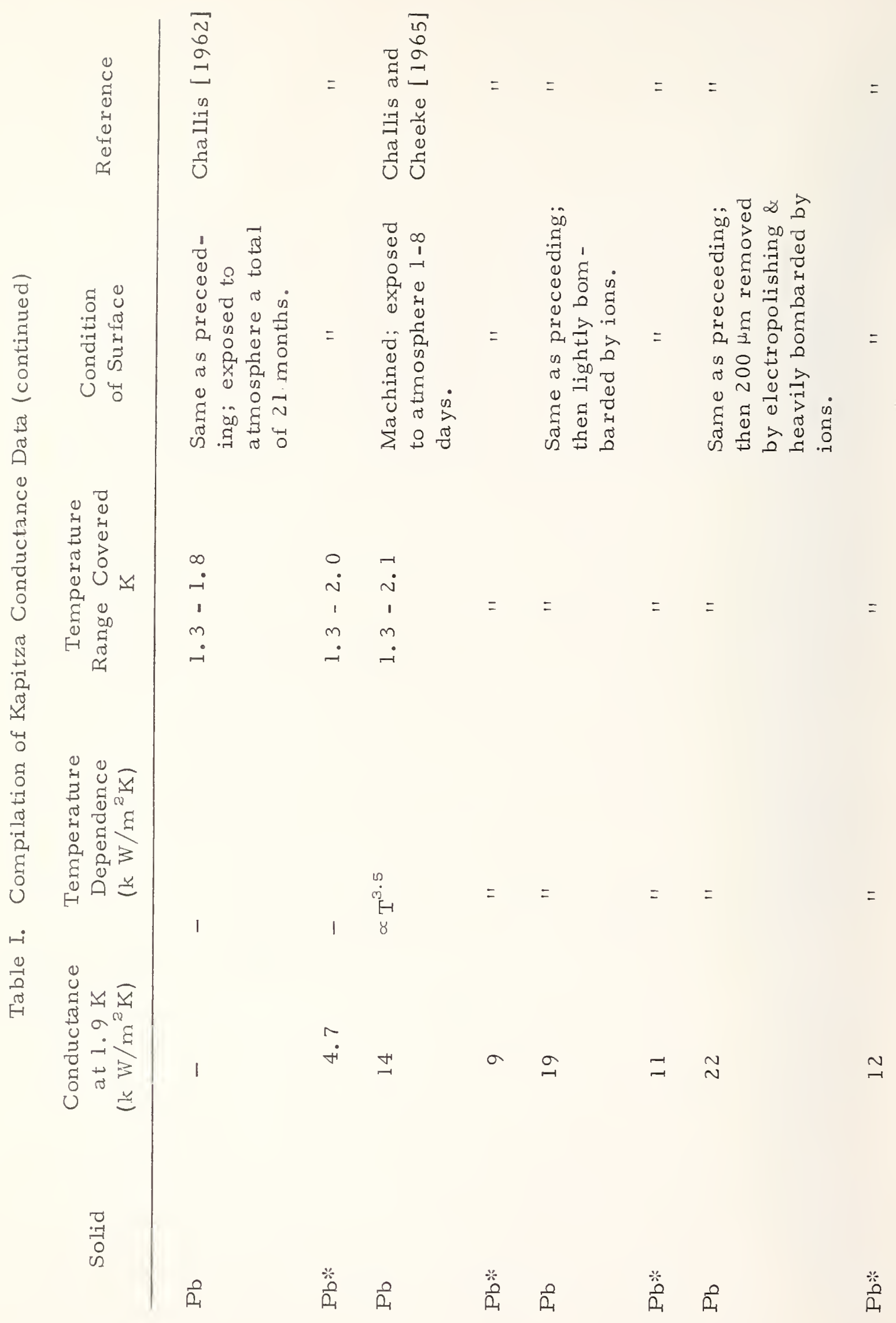




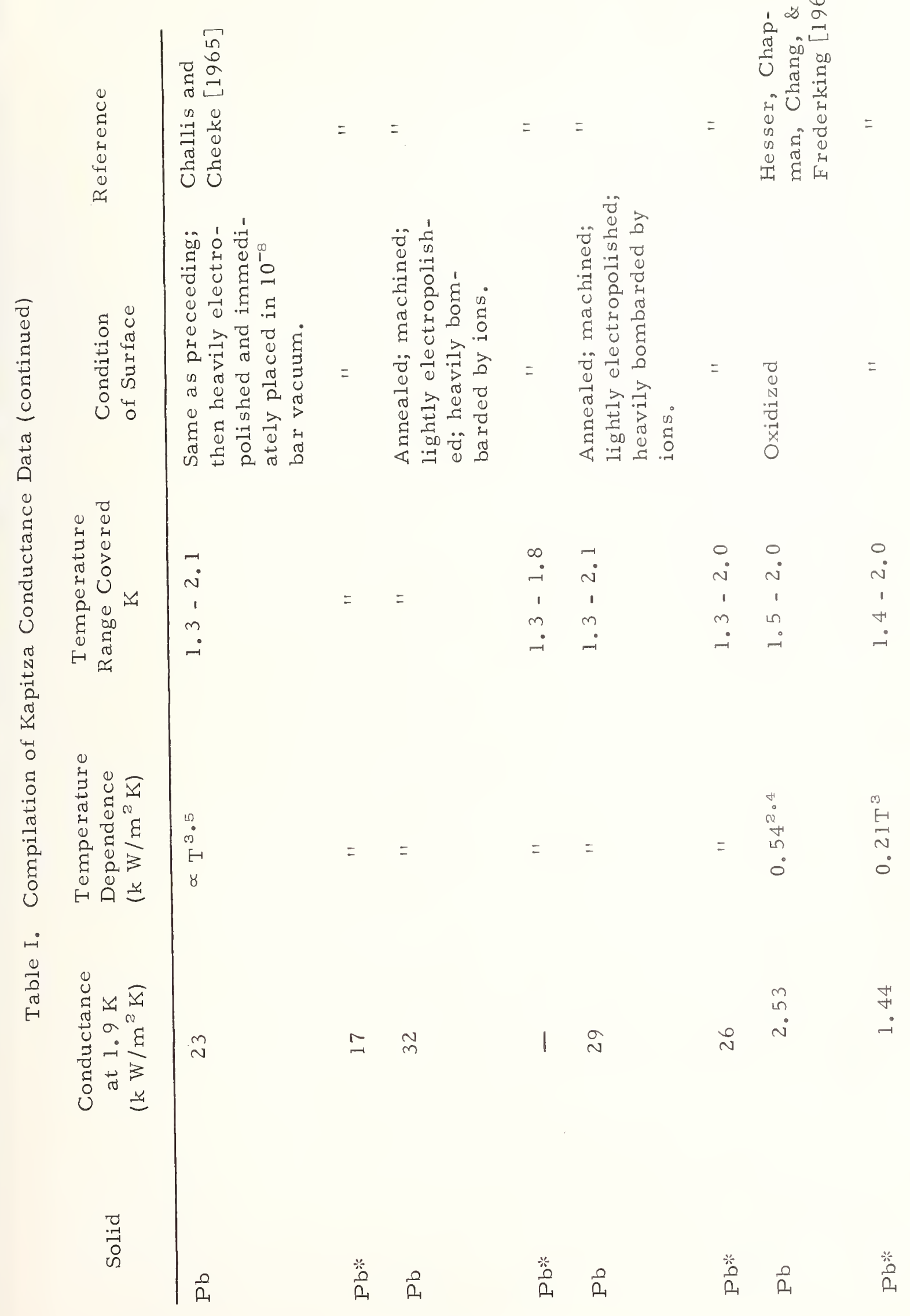




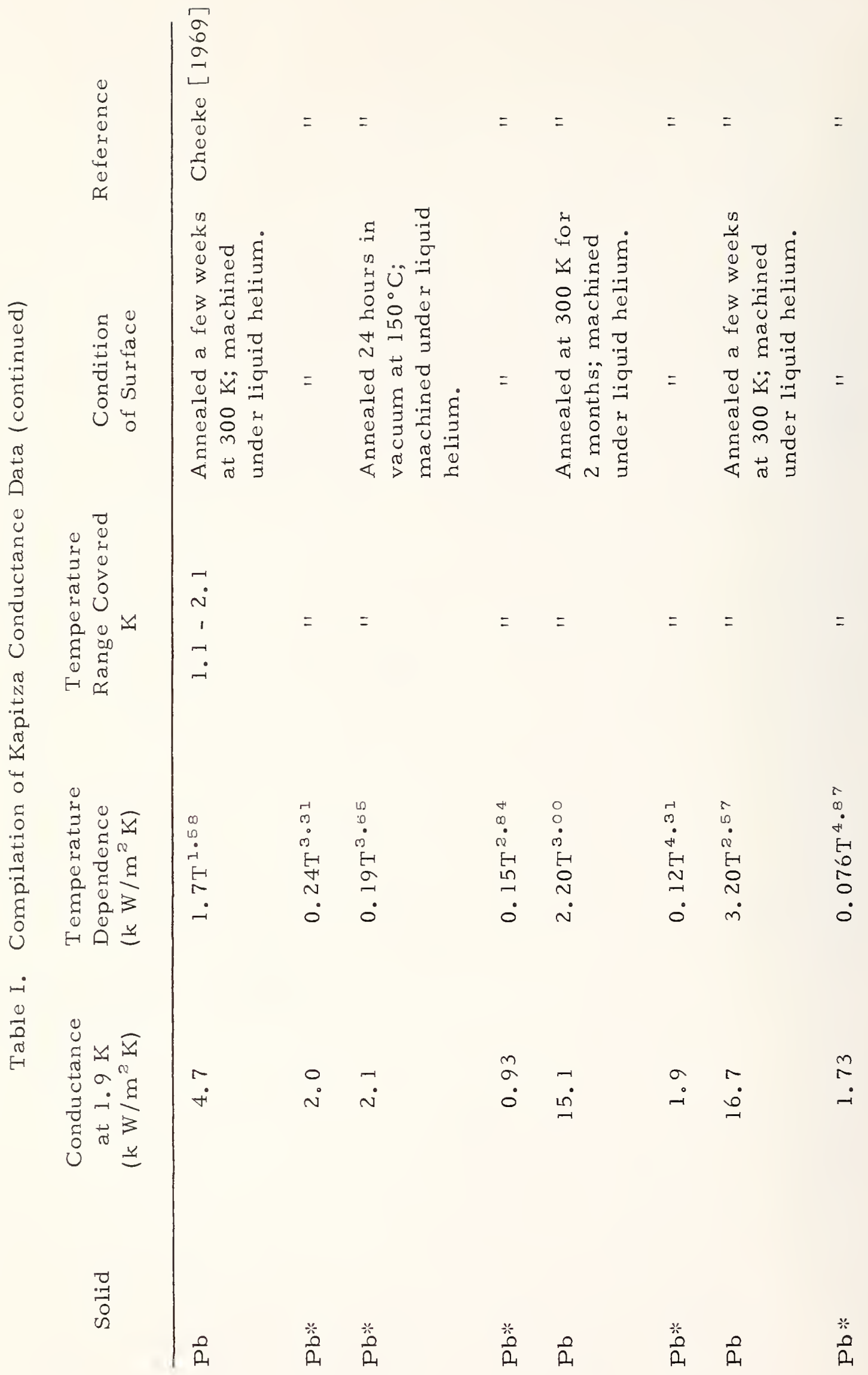




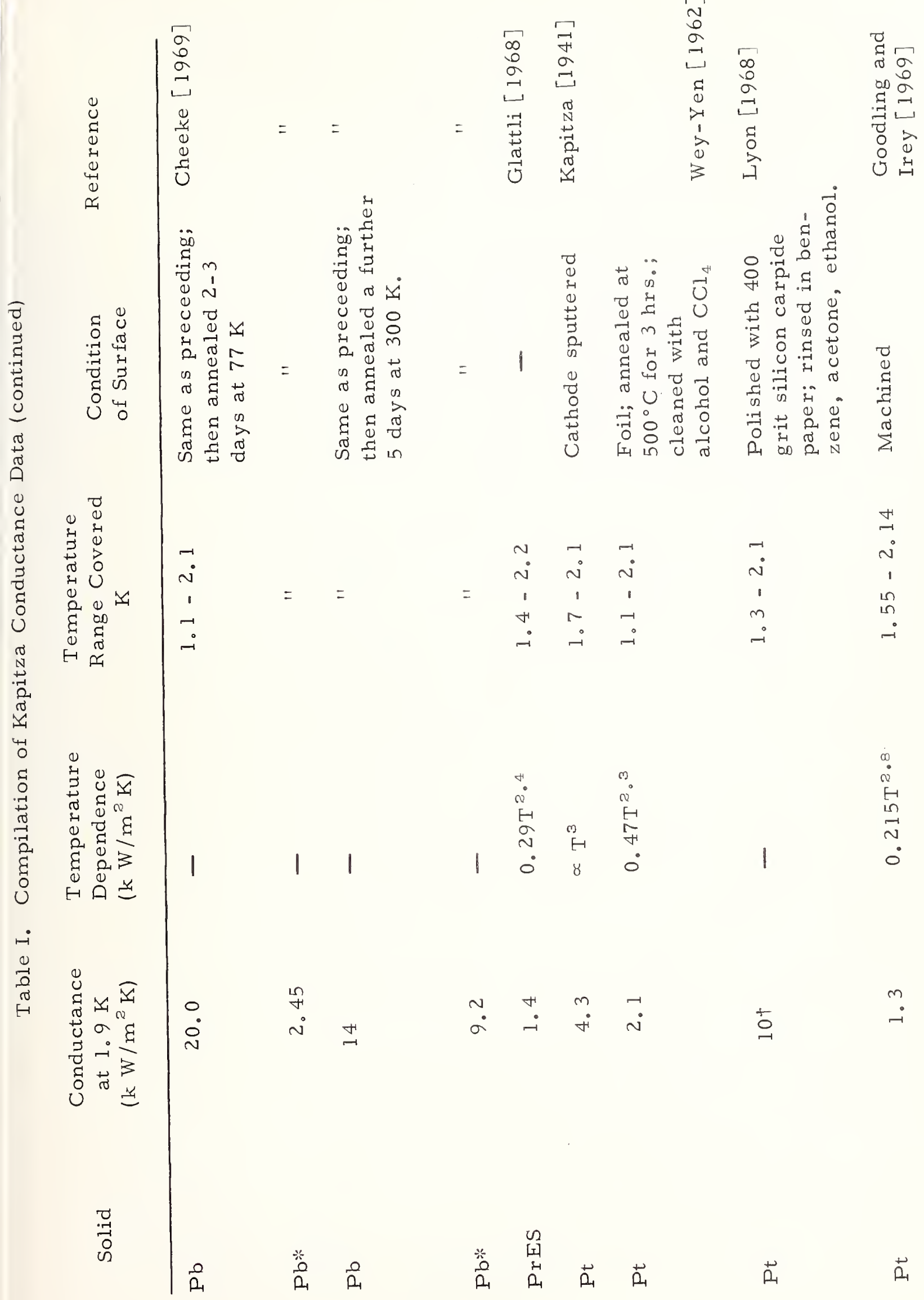




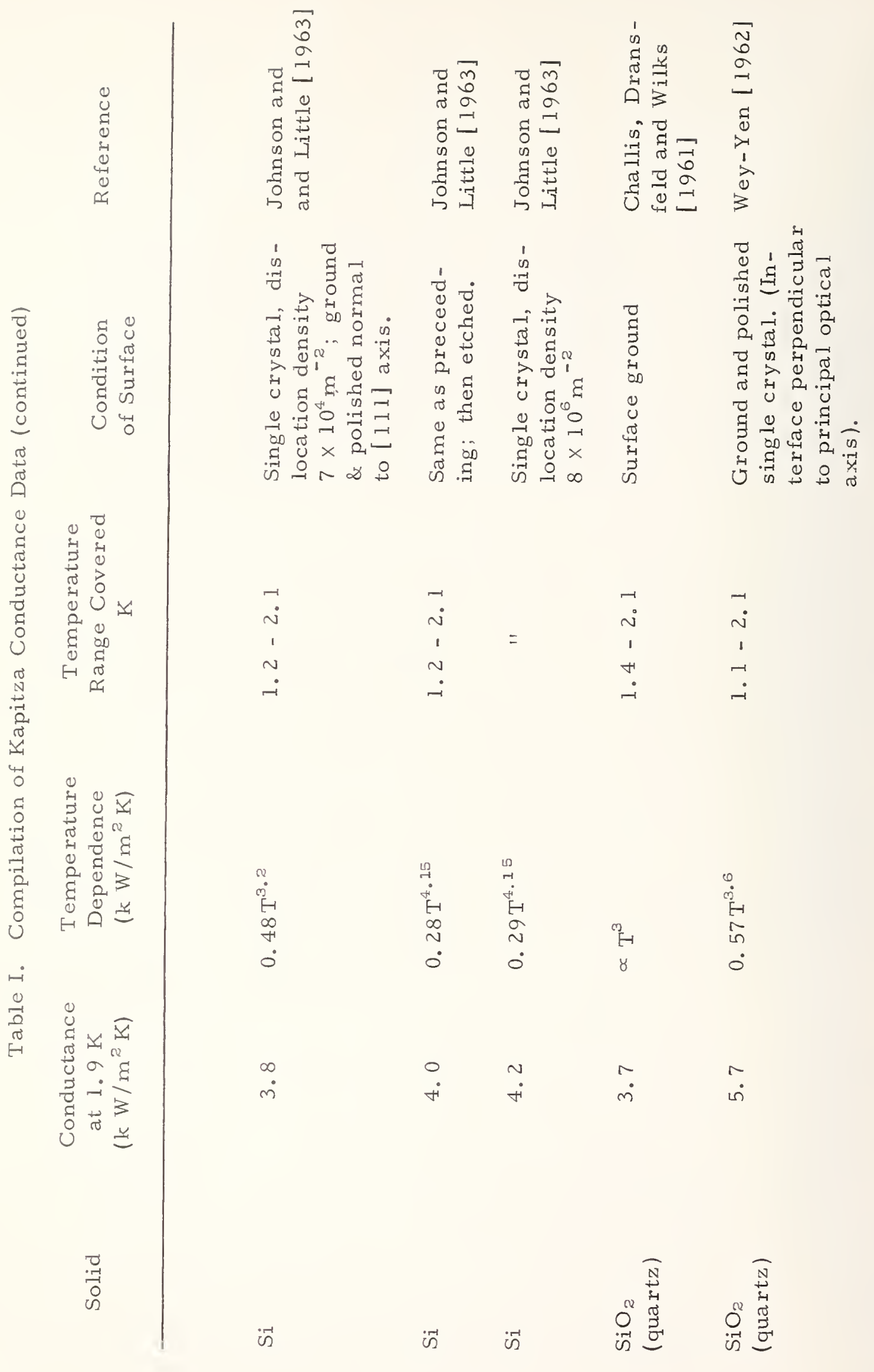




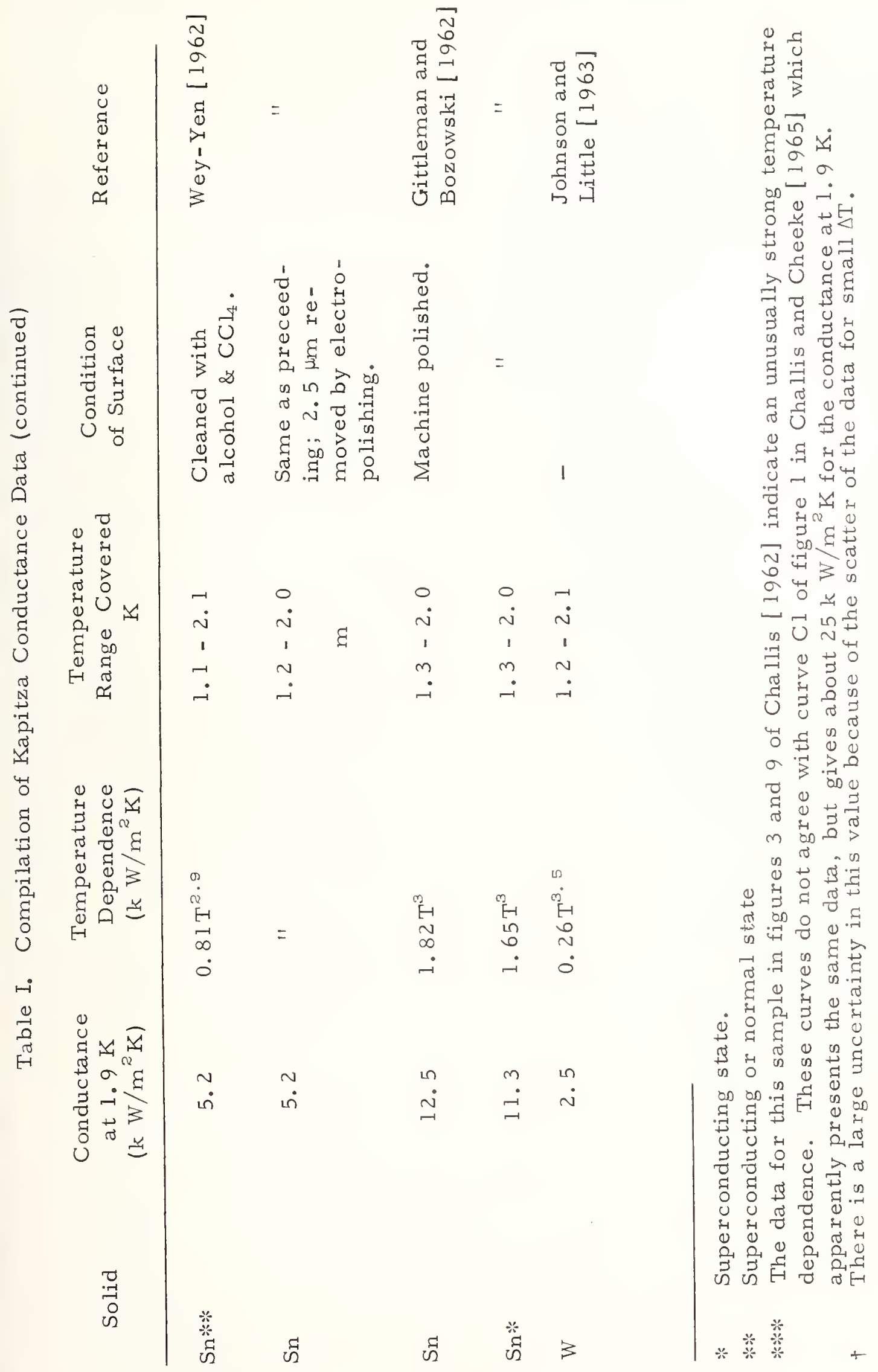


Table II. Comparison with Phonon Radiation Limit - Metals (1.9 K)

\begin{tabular}{|c|c|c|c|c|}
\hline Solid & $\theta_{D}$ & $\begin{array}{c}\text { Phonon Radiation } \\
\text { Limit for } \mathrm{h}_{\mathrm{K}}(1.9 \mathrm{~K}) \\
\left(\mathrm{k} \mathrm{W} / \mathrm{m}^{2} \mathrm{~K}\right)\end{array}$ & $\begin{array}{c}\text { Highest Observed } \\
h_{\mathrm{K}}(1.9 \mathrm{~K}) \\
\left(\mathrm{k} W / \mathrm{m}^{2} \mathrm{~K}\right)\end{array}$ & Reference \\
\hline $\mathrm{Hg}$ & 72 & 440 & 30 & $\begin{array}{l}\text { Neeper, Pearce } \\
\& \text { Wasilik [1967] }\end{array}$ \\
\hline $\mathrm{Pb}$ & 100 & 190 & 32 & $\begin{array}{l}\text { Challis \& Cheeke } \\
\text { [1965] }\end{array}$ \\
\hline In & 111 & 171 & 11 & $\begin{array}{l}\text { Neeper \& Dillin- } \\
\text { ger [ 1964] }\end{array}$ \\
\hline $\mathrm{Au}$ & 162 & 155 & 8.8 & $\begin{array}{l}\text { Johns on and } \\
\text { Little [ 1963] }\end{array}$ \\
\hline Pt & 221 & 62 & $10 t$ & Lyon $[1968]$ \\
\hline $\mathrm{Ag}$ & 226 & 55 & 6 & $\begin{array}{l}\text { Clement \& Fre- } \\
\text { derking [1965] }\end{array}$ \\
\hline $\mathrm{Sn}$ & 195 & 54 & 12.5 & $\begin{array}{l}\text { Gittleman \& } \\
\text { Bozowski [ 1962] }\end{array}$ \\
\hline $\mathrm{Cu}$ & 343 & 30 & 7.5 & $\begin{array}{l}\text { Johnson \& Little } \\
\text { [1963] }\end{array}$ \\
\hline $\mathrm{Ni}$ & 440 & 19 & 4.0 & Wey-Yen [1962] \\
\hline W & 405 & 18 & 2.5 & $\begin{array}{l}\text { Johnson \& Little } \\
\text { [1963] }\end{array}$ \\
\hline
\end{tabular}

t There is a large uncertainty in this value because of the scatter of the data for small $\Delta T$ 。 
Table III. Comparison with Phonon Radiation Limit - Non-Metals (1.9 K)

\begin{tabular}{|c|c|c|c|c|}
\hline Solid & $\Theta_{D}$ & $\begin{array}{l}\text { Phonon Radiation } \\
\text { Limit for } \mathrm{h}_{\mathrm{K}}(1.9 \mathrm{~K}) \\
\left(\mathrm{k} \mathrm{W} / \mathrm{m}^{2} \mathrm{~K}\right)\end{array}$ & $\begin{array}{c}\text { Highest Observed } \\
\mathrm{h}_{\mathrm{K}}(1.9 \mathrm{~K}) \\
\left(\mathrm{kW} / \mathrm{m}^{2} \mathrm{~K}\right)\end{array}$ & Reference \\
\hline $\mathrm{KCl}$ & 230 & 22 & 6.9 & Johnson [ 1964] \\
\hline $\begin{array}{l}\mathrm{SiO}_{2} \\
\text { (quartz) }\end{array}$ & 290 & 19 & 5.7 & Wey-Yen [1962] \\
\hline $\mathrm{Si}$ & 636 & 6.4 & 4.2 & $\begin{array}{l}\text { Johnson \& Little } \\
\text { [1963] }\end{array}$ \\
\hline $\mathrm{LiF}$ & 750 & 5.1 & 4.5 & $\begin{array}{l}\text { Johnson \& Little } \\
\text { [1963] }\end{array}$ \\
\hline $\mathrm{Al}_{2} \mathrm{O}_{3}$ & 1000 & 1.5 & 1.6 & $\begin{array}{l}\text { Gittleman \& } \\
\text { Bozowski [ 1962] }\end{array}$ \\
\hline
\end{tabular}


Table IV. Measurements of Kapitza Conductance for Copper [1.9 K]

Conductance

at $1.9 \mathrm{~K}$ $\left(\mathrm{kW} / \mathrm{m}^{2} \mathrm{~K}\right)$

7.5

7.3

\section{$7 \cdot 3$}

6.7

6.3

6.2

5.4

Machined; cleaned chem ically and rinsed in water \& ethanol; $85 \mathrm{~mm}^{2}$ of $154 \mathrm{~mm}^{2}$ machined under liquid helium; exposed to atmosphere 1 week at room temperature.

Same as preceeding except $47 \mathrm{~mm}^{2}$ of $161 \mathrm{~mm}^{2} \mathrm{ma}$ chined.

Machined; cleaned chemically \& rinsed in water \& ethanol; $47 \mathrm{~mm}^{2}$ of 161 $\mathrm{mm}^{2}$ machined under liquid helium.

Polished; washed in $\mathrm{NaOH}$ \& $\mathrm{CCl}_{4}$.

Machined; cleaned chemically and rinsed in water \& ethanol; $85 \mathrm{~mm}^{2}$ of $154 \mathrm{~mm}^{2}$ machined under liquid helium.

\section{0 Machined \\ Machined}

Etched with dilute $\mathrm{HNO}_{3}$ for 3 min.; exposed to atmos phere a few min.

4.2

Severely deformed by hammering; mechanically polished;

3.5 Same as preceeding; then cooled to liquid helium temperatures; annealed for 4 hrs. at $625^{\circ} \mathrm{C}$; lightly repolished mechanically.

\section{Temperature}

Dependence

Reference
Johnson \& Little [1963]
$\mathrm{T}^{3.1}$

$\mathrm{T}^{3.1}$

$\mathrm{T}$

$\mathrm{T}^{3.0}$

$T^{2 \cdot 7}$

Goodling \& Irey [1969]

Challis, Dransfeld \& Wilks
Johnson \&

Little [ 1963] 
Table IV. Measurements of Kapitza Conductance for Copper (1.9 K) (continued)

Conductance

at $1.9 \mathrm{~K}$

$\left(\mathrm{k} \mathrm{W} / \mathrm{m}^{2} \mathrm{~K}\right)$

2.7 Polished with jewelers rouge; exposed to atmosphere a few min.

2.6

2.3

1.2

\section{Condition}

of Surface
Temperature

Dependence

$$
\begin{aligned}
& T^{2.5} \\
& T^{2.6} \\
& T^{3} \\
& T^{2.6}
\end{aligned}
$$

Reference

Challis, Dransfeld, \& Wilks [ 1961]

Wey-Yen [ 1962]

Zinoveva [ 1953]

White, Gonzales, and Johnson [1953] 
Table V. Measurements of Kapitza Conductance for Lead in the Normal State $(1.9 \mathrm{~K})$

Conductance

at $1.9 \mathrm{~K}$

$\left(\mathrm{kW} / \mathrm{m}^{2} \mathrm{~K}\right)$

32

29

23

22

20.0

19

16.7

15.1
Condition

of Surface

Annealed; machined;

lightly electropolished;

heavily bombarded by ions.

Annealed; machined;

lightly electropolished;

heavily bombarded by

ions.

Freshly machined.

Machined; heavily electropolished and immediately placed in a $10^{-8}$

bar vacuum.

Machined; exposed to

atmosphere 8 days; lightly

bombarded by ions; 200

$\mu \mathrm{m}$ removed by electro-

polishing; heavily bom-

barded by ions.

Annealed a few weeks at

$300 \mathrm{~K}$; machined under

liquid helium; annealed

$2-3$ days at $77 \mathrm{~K}$.

Machined; exposed to

atmosphere 8 days; lightly

bombarded by ions.

Annealed a few weeks at

$300 \mathrm{~K}$; Machined under

liquid helium.

Annealed at $300 \mathrm{~K}$ for 2 months; machined under liquid helium.
Temperature

Dependence

Reference

$T^{3.5}$

Challis \&

Cheeke [ 1965]

II

11

$\mathrm{T}^{3.5}$

II

11

Cheeke [1969]

11

Challis \&

Cheeke [196́5]

$T^{2.07}$

Cheeke [19ó9] 
Table V. Measurements of Kapitza Conductance for Lead in the Normal State (1.9 K) (continued)

Conductance

at $1.9 \mathrm{~K}$

$\left(\mathrm{kW} / \mathrm{m}^{2} \mathrm{~K}\right)$
Condition

of Surface
Temperature

Dependence
Reference
15 Etched; exposed to atmosphere a few min.

$$
T^{3 \cdot 4}
$$

Challis, Dransfeld, \& Wilks [19ól].

Cheeke [1969]

Annealed a few weeks at $300 \mathrm{~K}$; machined under liquid helium; annealed $2-3$ days at $77 \mathrm{~K}$; annealed 5 days at $300 \mathrm{~K}$.

Machined; exposed to atmosphere 1-8 days.

$T^{3.5}$

$\mathrm{T}^{3}$

Machined; annealed in vacuum for $16 \mathrm{hrs}$, at $270^{\circ} \mathrm{C}$.

6.3

5.3

\section{7}

2.53
Machined; annealed in vacuum for 16 hrs. at $270^{\circ} \mathrm{C}$
Challis \&

Cheeke [1965]

Challis [196́2]

11

11

Cheeke [ 1969]

Hesser, Chapman, Chang \& Frederking [1969] 


\section{REFERENCES}

Abbe, W. J. (1967), Simple model for the Kapitza thermal resistance, Bull. Am. Phys. Soc. 12, No. 5, 708.

Abbe, W. J. (1968), A note on the Kapitza resistance, Nuovo Cimento 56B, No. 1, 187-189.

Anderson, A. C., J. I. Connolly, and J. C. Wheatley (1964), Thermal boundary resistance between solids and helium below $1 \mathrm{~K}$, Phys. Rev. 135, No. 4A, A910-A921.

Andreev, A. F. (1962a), Anomalous reflection of sound from the surface of a metal at low temperatures, Soviet Phys. - JETP 16, No. 1, 257-258, Transl. from Zh. Eksperim. i. Teor. Fiz. 43, No. 1, $358-360$.

Andreev, A. F. (1962b), The effect of conducting electrons on the Kapitza temperature jump, Soviet Phys. - JETP 16, No. 4, 1084-1088, Transl. from Zh. Eksperim. i. Teor. Fiz. 43, No. 4, 1535-1542.

Andronikashvili, E. L., and G. G. Mirskaia (1955), The behavior of helium II in the neighborhood of a heat radiating surface, Soviet Phys - JETP 2, No. 3, 406-409, Transl. from Zh. Eksperim. i. Teor. Fiz. 29, No. 4, 490-494.

Arp, V. D. (1970), Heat transport through helium II, Cryogenics (to be published).

Barnes, L. J., and J. R. Dillinger (1963), Thermal boundary resistance between some superconducting and normal metals, Phys. Rev. Letters 10, No. 7, 287-289.

Blackman, M. (1955), The specific heat of solids, Hand. der Phys. Vol. 7. Part 1, 325-382 (Springer-Verlag, Berlin). 
Brentari, E. G., P. J. Giarratano, and R. V. Smith (1965), Boiling heat transfer for oxygen, nitrogen, hydrogen, and helium, NBS Tech. Note No. 317, National Bureau of Standards, Boulder, Colo. Brow, N. J., and D. V. Osborne (1958), Heat transfer between copper and liquid helium II, Phil. Mag. 3, No. 36, 1463-1466.

Challis, L. J. (1961), The heat flow between metals and liquid helium II, Proc. 7th Intern. Conf. on Low Temperature Physics, 476-480, (University of Toronto Press, Toronto).

Challis, L. J. (1962), Some experiments on the Kapitza resistance between metals and liquid helium II, Proc. Phys. Soc. 80, Part 3, $759-767$.

Challis, L. J. (1964), On surface superconductivity in lead, Phys. Letters 13, No. 1, 20-21.

Challis, L. J. (1968), Experimental evidence for a dependence of the Kapitza conductance on the Debye temperature of a solid, Phys. Letters 26A, No. 3, 105-106。

Challis, L. J., and J. D. N. Cheeke (1965), The Kapitza conductance in lead, Prog. in Refrig. Sci. and Tech., Vol. I, 227-230 (Pergamon Press, London).

Challis, L. J., and J. D. N. Cheeke (1968), Some comments on the theory of the Kapitza conductance between metals and liquid helium II, Proc. Roy. Soc. A304, No. 1479, 479-486.

Challis, L. J., K. Dransfeld, and J. Wilks (1961), Heat transfer between solids and liquid helium II, Proc. Roy. Soc. A260, No. 1300, 31 -46.

Challis, L. J., and R. A. Sherlock (1969), Second sound measurements of the Kapitza boundary conductance to lead, Proc. ll th Intern. Conf. on Low Temperature Physics Vol. I, 571-574 (University of St. Andrews Printing Dept., St. Andrews, Scotland). 
Cheeke, J. D. N. (1969), The Kapitza conductance of lead, Proc. 11th Intern. Conf. on Low Temperature Physics, Vol I, 567-570 (University of St. Andrews Printing Dept., St. Andrews, Scotland). Clement, B. W., and T. H. K. Frederking (1965), Thermal boundary resistance and related peak flux during supercricial heat transport from a horizontal surface through a short tube to a saturated bath of liquid helium II, Liquid Helium Technology, Proc. Intern. Inst. Refrig. Commission I, Boulder, Colo., 1966, 49-59 (Pergamon Press, Oxford).

Devonshire, A. F. (1937), The interaction of atoms and molecules with solid surfaces. VIII - The exchange of energy between a gas and a solid, Proc. Roy. Soc. Al58, No. 894, 269-279.

Fairbank, H. A., and J. Wilks (1955), Heat transfer in liquid helium below $1 \mathrm{~K}$, Proc. Roy. Soc. A231, No. 1187, 545-554.

Frederking, T. H. K. (1961), Wärmeübergang bei der Verdampfung der verflüssigten Gase Helium und Stickstoff (Heat transfer with vaporization of liquid helium and nitrogen), Forschung 27, No. 1, 17-30 and No.2, 58-62.

Frederking, T. H. K. (1968), Thermal transport phenomena at liquid helium II temperatures, Chem. Eng. Prog. Symp. Series 64, No. $87,21-55$.

Frederking, T. H. K., and R. L. Haben (1968), Maximum low temperature dissipation rates of single horizontal cylinders in liquid helium II, Cryogenics 8, No. 1, 32-35 (1968).

Gittleman, J. I., and S. Bozowski (1962), Some aspects of the Kapitza resistance, Phys. Rev. 128, No. 2, 646-649. 
Glättli, H. (1968), Kapitza resistance of cerium ethyl sulphate, Can. J. Phys. 46, No. 2, 103-110.

Goodling, J. S., and R. K. Irey (1969), Non-boiling and film boiling heat transfer to a saturated bath of liquid helium, Advances in Cryogenic Engineering 14, 159-16́9 (Plenum Press, New York).

Goodman, F. O. (1968), Classical perturbation theory of the thermal accommodation coefficient in $\mathrm{n}$ dimensions, Surface Sci. 11 , No. $2,283-316$.

Goodman, F. O., and H. Y. Wachman (1967), Formula for thermal accommodation coefficients, J. Chem. Phys. 46, No. 6, 23762386.

Harris, R. E. (1967), On the determination of thermal accommodation coefficients in the temperature jump region, J. Chem. Phys. 46, No. $8,3217-3220$.

Hesser, R. J., R. C. Chapman, Y. W. Chang, T. H. K. Frederking (1969), Thermal boundary conductance between solids with impure surface and superfluid liquid helium II, A.I.Ch.E. Preprint 10, Eleventh National Heat Transfer Conference (American Institute of Chemical Engineers, New York).

Holdredge, R. M. , and P. W. McFadden (1966), Boiling heat transfer from cylinders in a saturated liquid helium II bath, Advances in Cryogenic Engineering 11, 507-515 (Plenum Press, New York).

Hurlbut, F. C. (1966), Current developments in the study of gas-surface interactions, Proc. 5th Intern. Symp. Rarefied Gas Dynamics, Vol. I, 1-34 (Academic Press, New York).

Irey, R. K., P. W. McFadden, and R. A. Madsen (1965), Heat transfer to a saturated bath of liquid helium II, Advances in Cryogenic Engineering 10, 361-370 (Plenum Press, New York). 
Johnson, R. C. (1964), Kapitza resistance of a crystal cleaved while immersed in liquid helium, Bull. Am. Phys. Soc. 9, No. 7, 713.

Johnson, R. C., and W. A. Little (1963), Experiments on the Kapitza resistance, Phys. Rev. 130, No. 2, 596-604.

Kapitza, P. L. (1941), The study of heat transfer in helium II, J. Phys. (Moscow) 4, No. 3, 181-210.

Khalatnikov, I. M. (1952), Heat exchange between a solid body and helium II, Zh. Eksperim. i. Teor. Fiz. 22, No. 6, 687-704.

Khalatnikov, I. M. (1965), Introduction to the Theory of Superfluidity, Chap. 23 (W. A. Benjamin, Inc., New York).

Kittel, C. (1966), Introduction to Solid State Physics, Chapters 5 and 6, third ed. (Wiley and Sons, New York).

Klemens, P. G. (1958), Lattice thermal conductivity, Solid State Physics 7, 1-98 (Academic Press, New York).

Lee, D. M. , and H. A. Fairbank (1959), Heat transport in liquid $\mathrm{He}^{3}$, Phys. Rev. 116, No. 6, 1359-1364.

Lemieux, G. P., and A. C. Leonard (1968), Maximum and minimum heat flux in helium II for a $76.2 \mu$ diameter horizontal wire at depths of immersion up to $70 \mathrm{~cm}$, Advances in Cryogenic Engineering 13, 624-631 (Plenum Press, New York).

Little, W. A. (1959), The transport of heat between dissimilar solids at low temperatures, Can. J. Phys. 37, No. 3, 334-349.

Little, W. A. (1960), The Kapitza resistance, Proc. 7 th Intern. Conf. on Low Temperature Physics, 482-483 (University of Toronto Press, Toronto). 
Little, W. A. (1961a), Kapitza resistance between helium and metals in the normal and superconducting states, Phys. Rev. 123, No.2, $435-441$.

Little, W. A. (1961b), Unimportance of surface roughness upon the Kapitza resistance, Phys. Rev. 123, No. 6, 1909-1911.

Little, W. A. (1962), The Kapitza resistance of metals in the normal and superconducting states, I. B. M. J.Res. Dev. 6, No. 1, 31-33.

Lyon, D. N. (1965), Boiling heat transfer and peak nucleate boiling fluxes in saturated liquid helium between the $\lambda$ and critical temperatures, Advances in Cryogenic Engineering 10, 37 1-379, (Plenum Press, New York).

Lyon, D. N. (1968), Pool boiling of cryogenic liquids, Chem. Eng. Prog. Symp. Series 64, No. 87, 82-92.

Madsen, R. A., and P. W. McFadden (1968), Heat transfer to an unsaturated bath of liquid helium II, Advances in Cryogenic Engineering 13, 617-623 (Plenum Press, New York).

Manchester, F. D. (1967), Solid layers in the adsorbed helium film and mobility of the film at low coverages, Rev. Mod. Phys. 39, No. 2, $383-394$.

Mate, C. F., and S. P. Sawyer (1968), Kapitza effect in gaseous helium, Phys. Rev. Letters 20, No. 16, 834-837.

Mate, C。F., \& S。P.Sawyer (1969), The Kapitza effect in the liquid and vapor phases of $\mathrm{He}^{3}$ and $\mathrm{He}^{4}$, Proc. Ilth Intern. Conf。 on Low Temperature Physics, Vol I, 579-581 (University of St. Andrews Printing Dept。, St. Andrews, Scotland)。 
Neeper, D. A., and J. R. Dillinger (1964), Thermal resistance at indiumsapphire boundaries between 1.1 and $2.1 \mathrm{~K}$, Phys. Rev. 135, No. 4A, A $1028-\mathrm{A} 1033$.

Neeper, D. A., D. C. Pearce, and R. M. Wasilik (1967), Kapitza resistance of mercury between 1.1 and $2.1 \mathrm{~K}$, Phys. Rev. 156, No. 3, $764-768$.

Peshkov, V. P. (1958), Observations of the $\lambda$-transition in helium in the presence of a thermal current through the phase boundary, Soviet Phys. -JETP 8, No. 6, 943-946, Trasl. from Zh. Eksperim. i. Teor. Fiz。 35, No. 6, 1350-1354.

Pollack, G. L. (1969), Kapitza resistance, Rev. Mod. Phys. $\underline{41}$, No. 1, $48-81$.

Rivers, W. J., and P. W. McFadden (1966), Film free convection in helium II, J. Heat Trans., Trans, of the ASME Ser. C $\underline{88}$, No. 4, 343-350.

Roberts, J. K. (1932), The exchange of energy between gas atoms and solid surfaces. II - The temperature variation of the accommodation coefficient of helium, Proc. Roy. Soc. A135, No. 826, 192-205.

Rorschach, H. E., and F. A. Romberg (1957), Pressure gradients produced by heat flow in liquid helium, Proc. 5th Intern. Conf. on Low Temperature Physics and Chemistry, 35-38 (University of Wisconsin Press, Madison).

Rosenberg, H. M. (1963), Low Temperature Solid State Physics, Section 5.13 (Clarendon Press, Oxford).

Singh, R. P., and W. Band (1955), The anomalous monolayer adsorption of helium, J. Phys. Chem. 59, No. 7, 663-665. 
Smoluchowski, M. (1898), Conduction of heat by rarefied gases, Phil. Mag. 46, No. 279, 192-206.

Steele, W. A. (1956), Concerning a theory of multilayer adsorption, with particular reference to adsorbed helium, J. Chem. Phys. 25, No. 5, 819-823.

Suomi, M。, A. C. Anderson, and B. Holmström (1968), Heat transfer below 0.2 K, Physica 38, No. 1, 67-80.

Thomas, L。B. (1966), A collection of some controlled surface thermal accommodation coefficient measurements, Proc. 5th Intern. Symp. Rarefied Gas Dynamics, Vol. I, 155-162 (Academic Press, New York).

Thomas, L. B., and E. B. Schofield (1955), Thermal accommodation coefficient of Helium on a bare tungsten surface, J. Chem. Phys. 23, No. 5, $861-866$.

Von Gutfeld, R. J., A. H. Nethercot, Jr., and J. A. Armstrong (1966), Transport of heat from metals to insulators at low temperatures, Phys. Rev。142, No. 2, 436-441.

Wachman, H. Y。(196́2), The thermal accommodation coefficient: A critical survey, Am. Rocket Soc, J. 32, No, 1, 2-12。

Wey-Yen, K. (196́2), Investigation of the temperature discontinuity at the boundary between a solid and superfluid helium, Soviet Phys。JETP 15, No. 4, 6́35-645, Transl. from Zh. Eksperim. i. Teor. Fiz. 42, No. 4, $921-935$.

Whelan, M. F., and D. V. Osborne (1969), The modification of the Kapitza resistance due to a surface film, Proc. llth Intern. Conf. on Low Temperature Physics, Vol. I, 575-578 (University of St. Andrews Printing Dept., St. Andrews, Scotland). 
White, D。, O. D. Gonzales, and H. L. Johnston (1953), Heat conduction of the boundary layer in liquid helium II, Phys。Rev. $\underline{89}$, No. 3, 593-594.

Wilks, J。 (1967), The Properties of Liquid and Solid Helium, (Clarendon Press, Oxford).

Woods, A. D. B. (1965), Neutron inelastic scattering from liquid helium at small momentum transfers, Phys. Rev. Letters 14, No. 10, 355-356。

Young, F. W. Jr。, and T. R. Wilson (1961), Acid cutting and acid polishing of copper crystals, Rev. Sci. Instrum。 32, No. 5, $559-562$ 。

Zinoveva, K. N。(1953), Zh. Eksperim. i. Theor. Fiz. 25, 235. 


\section{PERIODICALS}

JOURNAL OF RESEARCH reports National Bureau of Standards research and development in physics, mathematics, chemistry, and engineering. Comprehensive scientific papers give complete details of the work, including laboratory data, experimental procedures, and theoretical and mathematical analyses. Illustrated with photographs, drawings, and charts.

Published in three sections, available separately:

\section{Physics and Chemistry}

Papers of interest primarily to scientists working in these fields. This section covers a broad range of physical and chemical research, with major emphasis on standards of physical measurement, fundamental constants, and properties of matter. Issued six times a year. Annual subscription: Domestic, $\$ 9.50$; foreign, $\$ 11.75^{*}$.

\section{Mathematical Sciences}

Studies and compilations designed mainly for the mathematician and theoretical physicist. Topics in nathematical statistics, theory of experiment design, numerical analysis, theoretical physics and chemistry, logical design and programming of computers and computer systems. Short numerical tables. Issued quarterly. Annual subscription: Domestic, $\$ 5.00$; foreign, $\$ 6.25^{*}$.

\section{Engineering and Instrumentation}

Reporting results of interest chiefly to the engineer and the applied scientist. This section includes many of the new developments in instrumentation resulting from the Bureau's work in physical measurement, data processing, and development of test methods. It will also cover some of the work in acoustics, applied mechanics, building research, and cryogenic engineering. Issued quarterly. Annual subscription: Domestic, $\$ 5.00$; foreign, $\$ 6.25^{*}$.

\section{TECHNICAL NEWS BULLETIN}

The best single source of information concerning the Bureau's research, developmental, cooperative and publication activities, this monthly publication is designed for the industry-oriented individual whose daily work involves intimate contact with science and technology-for engineers, chemists, physicists, research managers, product-development managers, and company executives. Annual subscription: Domestic, $\$ 3.00$; foreign, $\$ 4.00^{*}$.

\section{NONPERIODICALS}

Applied Mathematics Series. Mathematical tables, manuals, and studies.

Building Science Series. Research results, test methods, and performance criteria of building materials, components, systems, and structures.

Handbooks. Recommended codes of engineering and industrial practice (including safety codes) developed in cooperation with interested industries, professional organizations, and regulatory bodies.

Special Publications. Proceedings of NBS conferences, bibliographies, annual reports, wall charts, pamphlets, etc.

Monographs. Major contributions to the technical literature on various subjects related to the Bureau's scientific and technical activities.

\section{National Standard Reference Data Series. NSRDS provides quantitive data on the physical and chemical properties of materials, compiled from the world's literature and critically evaluated.}

Product Standards. Provide requirements for sizes, types, quality and methods for testing various industrial products. These standards are developed cooperatively with interested Government and industry groups and provide the basis for common understanding of product characteristics for both buyers and sellers. Their use is voluntary.

Technical Notes. This series consists of communications and reports (covering both other agency and NBS-sponsored work) of limited or transitory interest.

Federal Information Processing Standards Publications. This series is the official publication within the Federal Government for information on standards adopted and promulgated under the Public Law 89-306, and Bureau of the Budget Circular A-86 entitled, Standardization of Data Elements and Codes in Data Systems.

\section{CLEARINGHOUSE}

The Clearinghouse for Federal Scientific and Technical Information, operated by NBS, supplies unclassified information related to Government-generated science and technology in defense, space, atomic energy, and other national programs. For further information on Clearinghouse services, write:

Clearinghouse

U.S. Department of Commerce

Springfield, Virginia 22151

* Difference in price is due to extra cost of foreign mailing.

Order NBS publications from:

Superintendent of Documents

Government Printing Office

Washington, D.C. 20402 
U.S. DEPARTMENT OF COMMERCE

WASHINGTON, D.C. 20230

OFFICIAL BUSINESS 